ARTICLE

\title{
SCN4B acts as a metastasis-suppressor gene preventing hyperactivation of cell migration in breast cancer
}

Emeline Bon ${ }^{1}$, Virginie Driffort ${ }^{1}$, Frédéric Gradek${ }^{1}$, Carlos Martinez-Caceres ${ }^{2}$, Monique Anchelin ${ }^{3}$, Pablo Pelegrin ${ }^{2}$, Maria-Luisa Cayuela ${ }^{3}$, Séverine Marionneau-Lambot ${ }^{4}$, Thibauld Oullier ${ }^{4}$, Roseline Guibon ${ }^{1,5}$, Gaëlle Fromont ${ }^{1,5}$, Jorge L. Gutierrez-Pajares ${ }^{1}$, Isabelle Domingo ${ }^{1}$, Eric Piver ${ }^{5,6}$, Alain Moreau ${ }^{6}$, Julien Burlaud-Gaillard ${ }^{7}$, Philippe G. Frank ${ }^{1}$, Stéphan Chevalier ${ }^{1,8, *}$, Pierre Besson ${ }^{1,8, \star} \&$ Sébastien Roger ${ }^{1,9,10, *}$

The development of metastases largely relies on the capacity of cancer cells to invade extracellular matrices (ECM) using two invasion modes termed 'mesenchymal' and 'amoeboid', with possible transitions between these modes. Here we show that the SCN $4 B$ gene, encoding for the $\beta 4$ protein, initially characterized as an auxiliary subunit of voltage-gated sodium channels $\left(\mathrm{Na} \mathrm{a}_{\mathrm{V}}\right.$ ) in excitable tissues, is expressed in normal epithelial cells and that reduced $\beta 4$ protein levels in breast cancer biopsies correlate with high-grade primary and metastatic tumours. In cancer cells, reducing $\beta 4$ expression increases RhoA activity, potentiates cell migration and invasiveness, primary tumour growth and metastatic spreading, by promoting the acquisition of an amoeboid-mesenchymal hybrid phenotype. This hyperactivated migration is independent of $\mathrm{Na}_{\mathrm{V}}$ and is prevented by overexpression of the intracellular $C$-terminus of $\beta 4$. Conversely, SCN $4 B$ overexpression reduces cancer cell invasiveness and tumour progression, indicating that $S C N 4 B / \beta 4$ represents a metastasis-suppressor gene.

\footnotetext{
${ }^{1}$ Inserm UMR1069, Nutrition, Croissance et Cancer, Université François-Rabelais de Tours, 10 Boulevard Tonnellé, 37032 Tours, France. ${ }^{2}$ Inflammation and Experimental Surgery Unit, CIBERehd, Murcia's BioHealth Research Institute IMIB-Arrixaca, Clinical University Hospital Virgen de la Arrixaca, E-30120 Murcia, Spain. ${ }^{3}$ Telomerase, Cancer and Aging Group, Hospital Virgen de la Arrixaca, E-30120 Murcia, Spain. ${ }^{4}$ Cancéropôle du Grand Ouest, Plateforme In Vivo, 44000 Nantes, France. ${ }^{5}$ CHRU de Tours, 2 Boulevard Tonnellé, 37000 Tours, France. ${ }^{6}$ Inserm, U966, Université François-Rabelais de Tours, 10 Boulevard Tonnellé, 37032 Tours, France. ${ }^{7}$ Laboratoire de Biologie Cellulaire-Microscopie Electronique, Faculté de Médecine, Université François-Rabelais de Tours, 2 Boulevard Tonnellé, 37000 Tours, France. ${ }^{8}$ UFR Sciences Pharmaceutiques, Université François-Rabelais de Tours, 31 Avenue Monge, 37200 Tours, France. ${ }^{9}$ UFR Sciences et Techniques, Département de Physiologie Animale, Université François-Rabelais de Tours, Parc de Grandmont, 37200 Tours, France. ${ }^{10}$ Institut Universitaire de France, 1, Rue Descartes, 75231 Paris Cedex 05, France. ${ }^{\star}$ These authors contributed equally to this work. Correspondence and requests for materials should be addressed to S.R. (email: sebastien.roger@univ-tours.fr).
} 
T he acquisitions of extensive invasion potencies by cancer cells are key components in the metastatic cascade, hence in patients survival ${ }^{1,2}$. During the last decade, important knowledge in various processes of cancer cell migration and invasiveness has emerged ${ }^{3}$. In the 'mesenchymal mode', engaged cells harbour an elongated fibroblast-like morphology, with a rear-to-front lamellopodial cell polarity, and generate a path in the extracellular matrix (ECM) through proteolytic remodelling. This is performed by invadosomal structures, which are F-actinrich organelles, protrusive into the ECM and responsible for its proteolysis through the recruitment of both membrane-associated and extracellularly released soluble proteases ${ }^{4,5}$. In the other invasive mode, called 'amoeboid', cancer cells show no obvious polarity but a rounded morphology, and display high potentials for migration and invasiveness ${ }^{6}$. In this case, strong actomyosin contractions propel the cell, which deforms and squeezes inside small gaps of the ECM, with no need to degrade it. While different cancer cell types may preferentially engage into the mesenchymal mode or the amoeboid one, the most aggressive cancer cells show high plasticity and are able to switch from one phenotype to the other ${ }^{6}$. Such transitions, orchestrated by RhoGTPases family members ${ }^{7-9}$, offer selective advantages and compensatory mechanisms to migrating cancer cells, presumably abrogating the efficacy of anticancer treatments ${ }^{10}$. Indeed, attempts to reduce cancer cell invasiveness and metastatic dissemination by targeting proteolytic activity and ECM remodelling have largely failed because of the adaptive compensatory mechanism sustaining protease-independent processes ${ }^{11}$.

Voltage-gated sodium channels $\left(\mathrm{Na}_{\mathrm{V}}\right)$ are composed of one large pore-forming principal subunit (nine genes encoding nine proteins, $\left.\mathrm{Na}_{\mathrm{V}} 1.1-1.9\right)^{12,13}$ and one or two smaller transmembrane subunits considered as auxiliary (four genes $S C N 1 B$ to $S C N 4 B$, generating four subunits, $\beta 1$ to $\beta 4)^{14}$. The activity of $\mathrm{Na}_{\mathrm{V}}$ gives rise to $\mathrm{Na}^{+}$currents $\left(I_{\mathrm{Na}}\right)$ generating action potentials in excitable cells such as neurons, skeletal and cardiac muscle cells. As a result, these proteins have been considered hallmarks of excitable cells. However, multiple studies have recently demonstrated their expression in non-excitable cells, in which they regulate cellular functions such as migration, differentiation, endosome acidification, phagocytosis and podosome formation ${ }^{15}$. In addition, $\mathrm{Na}_{\mathrm{V}}$ are abnormally expressed in carcinoma cells and tumour biopsies, and their activity is associated with aggressive features and cancer progression $^{16-18}$. Expression of the $\mathrm{Na}_{\mathrm{V}} 1.5$ isoform in breast tumours is correlated with metastases development and patients' death ${ }^{19,20}$. In highly aggressive human breast cancer cells, the activity of pore-forming $\mathrm{Na}_{\mathrm{V}} 1.5$ is not associated with cell excitability but with ECM degradation and cancer cell invasiveness ${ }^{21}$, hence favouring metastases development ${ }^{22,23}$. $\mathrm{Na}_{\mathrm{V}}$ 1.5-dependent invasiveness is mediated through allosteric modulation of the $\mathrm{Na}^{+}-\mathrm{H}^{+}$exchanger NHE1, subsequent acidification of the pericellular microenvironment and activation of extracellular acidic cysteine cathepsins ${ }^{24-26}$. Furthermore, $\mathrm{Na}_{\mathrm{V}} 1.5$ sustains $\mathrm{Src}$ kinase activity, polymerization of actin and acquisition by cells of a spindleshaped elongated morphology ${ }^{26}$. Altogether, these results indicate a critical role for $\mathrm{Na}_{\mathrm{V}} 1.5$ in 'mesenchymal invasion'. The participation of non-pore-forming $S C N x B / \beta$ subunits in oncogenic processes was not studied as extensively, with the exception of the $\beta 1$ subunit ${ }^{27}$, and their roles during metastatic progression remain largely unknown.

In this study, we show that the $S C N 4 B / \beta 4$ subunit is expressed in normal epithelial cells and tissues, but is strongly downregulated in aggressive cancer cells and tumours. The loss of $S C N 4 B / \beta 4$ enhances cancer cell migration and metastases formation through a RhoA-dependent signalling pathway, independently of pore-forming $\mathrm{Na}_{\mathrm{V}}$ subunits.

\section{Results}

Association with poor prognosis. Expression of the $\beta 4$ protein, encoded by the $S C N 4 B$ gene ${ }^{28}$, has mostly been studied in excitable cells in which mutations have been linked to sodium channelopathies ${ }^{29,30}$. Initial immunohistochemical analyses performed in normal and cancer breast tissues indicated that the $S C N 4 B / \beta 4$ protein was specifically expressed in epithelial cells from normal mammary acini, but was significantly downregulated in cancer cells (Fig. 1a,b). Levels of $\beta 4$ expression were analysed by immunohistochemistry on tissue microarrays containing normal breast, hyperplasic, dysplasia, breast cancer and lymph node metastases (LNM) samples. Again, the expression of $S C N 4 B / \beta 4$ was strong in epithelial cells from normal non-excitable mammary tissues (Fig. 2a,b), as well as in breast hyperplasia (Supplementary Fig. 1). Levels of $S C N 4 B / \beta 4$ expression in mammary hyperplasia and dysplasia were similar to those recorded in normal mammary tissues, but were remarkably reduced in biopsies of mammary carcinomas. The most important reductions in $S C N 4 B / \beta 4$ expression were observed when comparing in situ grade I to invasive grade II breast

a

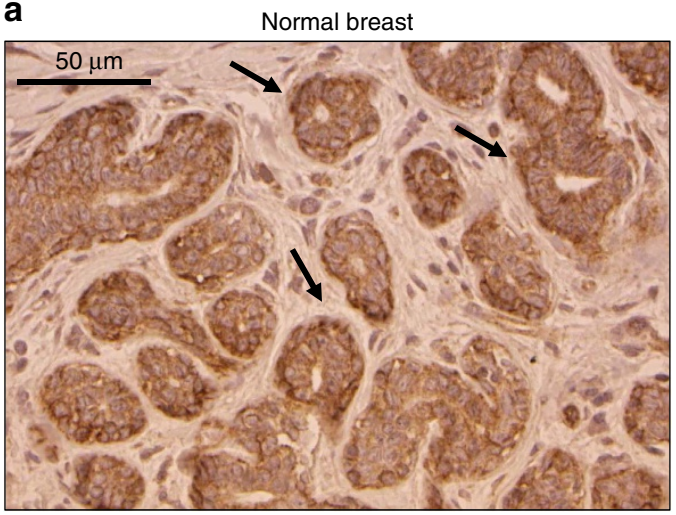

b

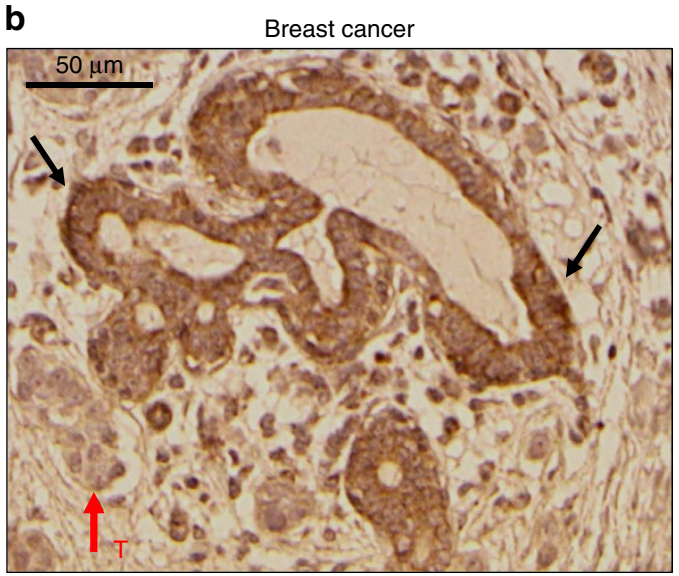

Figure 1 | SCN4B/\$4 protein is expressed in normal epithelial cells of human breast tissues and is downregulated in cancer cells.

$(\mathbf{a}, \mathbf{b}) \beta 4$ protein (expression of the SCN4B gene) was analysed by immunohistochemistry on human breast tissue samples. (a) The expression of $\beta 4$ protein was strong in epithelial cells of mammary acini (some examples are indicated by the black arrows), and not in non-epithelial cells of normal breast tissues. (b) In breast cancer tissue, the expression of $\beta 4$ protein was strong in normal epithelial cells of mammary acini (black arrows), but significantly reduced in cancer cells (tumour area indicated by the red arrow, ' $T$ '). Scale bars, $50 \mu \mathrm{m}$. 

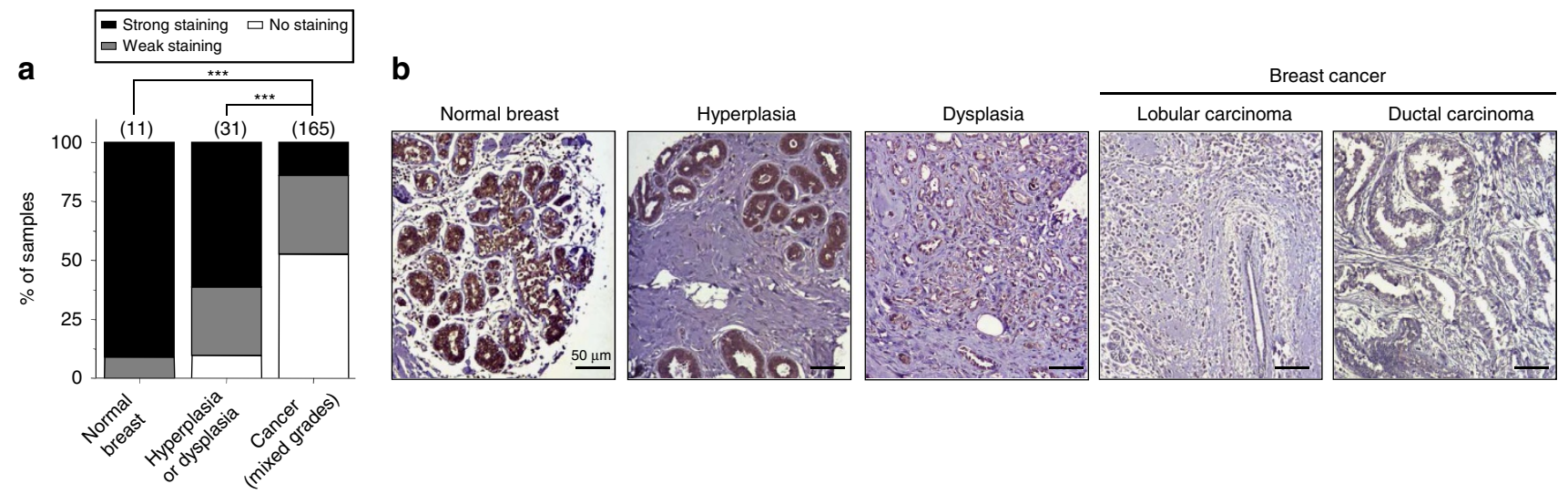

C

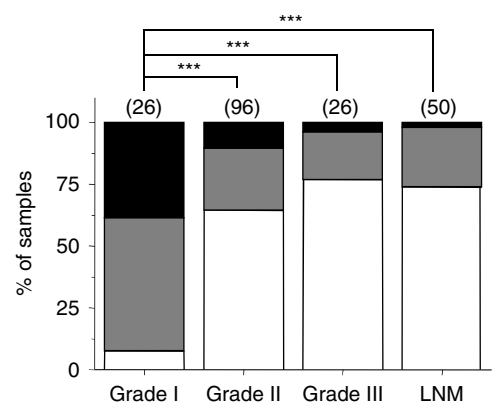

e

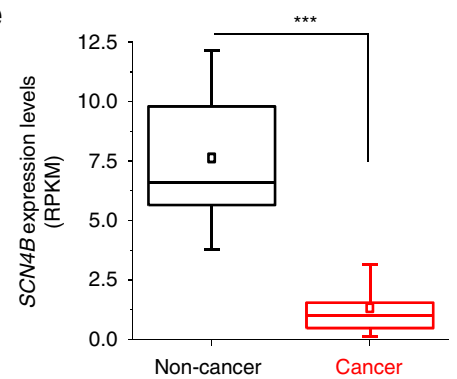

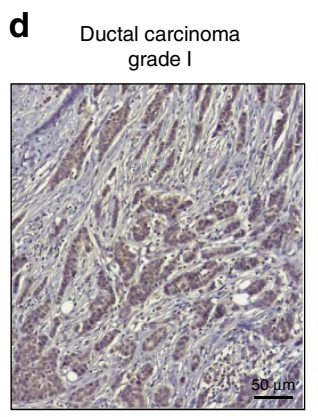

f

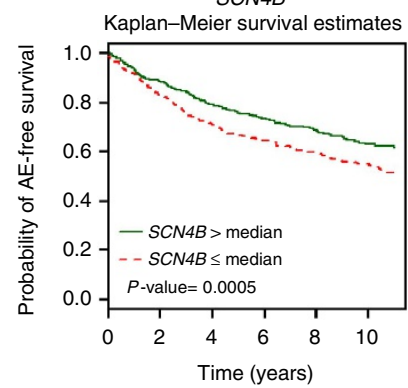

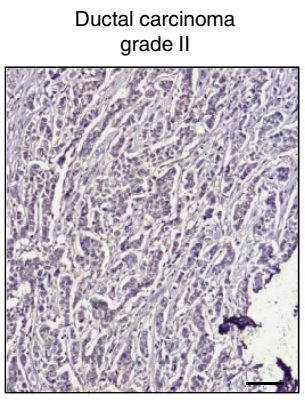

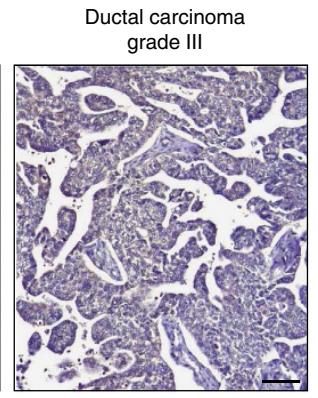

g

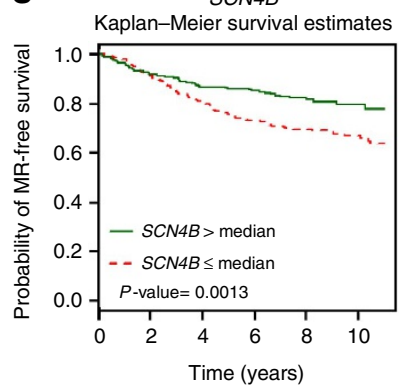

Figure 2 | SCN4B down regulation in human breast cancer tissues associates with poor prognosis. (a-d) $S C N 4 B / \beta 4$ protein expression was analysed by immunohistochemistry on breast tissue microarrays. Samples were stratified in 'no staining', 'weak staining' or 'strong staining' groups. (a) Proportion of samples showing no (white), weak (gray) or strong (black) $\beta 4$ staining in normal breast, compared with mammary hyperplasia/dysplasia and cancer (mixed grades) samples. The number of samples per condition is indicated in brackets. $S C N 4 B / \beta 4$ protein staining was stronger in normal compared with cancer samples $\left(\chi^{2}, P<0.001\right)$, and in hyperplasia/dysplasia compared with cancer samples $\left(\chi^{2}, P<0.001\right)$. (b) SCN4B/ $\beta 4$ staining from indicated samples. Scale bars, $50 \mu \mathrm{m}$. (c) Proportion of samples showing no, weak or strong SCN4B/ $\beta 4$ staining in cancer samples, from grade I to III, and in lymph node metastases (LNM) samples. The number of samples per condition is indicated in brackets. $\beta 4$ staining was stronger in grade I cancer samples compared with more advanced cancer samples (grades II, III and LNM) $\left(\chi^{2}, P<0.001\right)$. (d) Representative pictures of $\beta 4$ staining from grade I, II and III ductal carcinoma samples. Scale bars, $50 \mu \mathrm{m}$. (e) Expression of the SCN4B gene in non-cancer $(n=29)$ and in invasive breast carcinoma tissues $(n=145)$ was analysed from The Cancer Genome Atlas (TCGA). RNA level is expressed as reads per kilobase per million (RPKM). Box plots indicate the first quartile, the median and the third quartile; whiskers indicate minimum and maximum values; squares show the means. SCN4B gene was significantly downregulated in cancer tissues (Mann-Whitney rank sum test, $M W, P<0.001$ ). (f,g) Prognostic analyses of gene expression in breast cancers, performed using the Breast Cancer Gene-Expression Miner. (f) Kaplan-Meier Any Event (AE)-free survival analyses, performed on data pooled from cohorts for the expression of SCN4B gene ( $n=1,024$ patients). AE is defined as being metastatic relapse (MR) or patient death. A weak expression of SCN4B gene ( $\leq$ median of the pooled cohorts) was associated with a decrease in the AE-free survival $(P=0.0005)$. (g) Kaplan-Meier MR-free survival analyses were performed for the expression of SCN4B ( $n=661$ patients). A weak expression of SCN4B ( $\leq$ median of the pooled cohorts) was associated with a decrease in the MR-free survival $(P=0.0013)$. Cox results are displayed on the graph.

tumours. $S C N 4 B / \beta 4$ protein was weakly expressed or totally absent in most grade II and III primary tumours studied, as well as in LNM (Fig. 2c,d). Lower levels of the $S C N 4 B$ gene transcript in breast cancer tissues, compared with non-cancer tissues, were also found to be highly significant in RNA sequence expression analysed from The Cancer Genome Atlas Network (Fig. 2e) and to be associated with an increased risk of metastatic relapse or death in breast cancer patients (Fig. 2f,g). Levels of expression of the other $S C N x B$ genes were also assessed. Expressions of $S C N 1 B$, $S C N 2 B$ and $S C N 3 B$ were lower in cancer compared with non-cancer tissues (Supplementary Fig. 2a,c,e). However, there was no association between the levels of expression of these genes and the risk of metastatic relapse (Supplementary Fig. 2b,d and f). Importantly, $S C N 1 B$ and $S C N 4 B$ genes appeared to be the two most highly expressed $S C N x B$ genes in non-cancer tissues (Supplementary Fig. 2g). Furthermore, SCN4B seemed to be the 
most significantly downregulated $S C N x B$ gene in breast cancer tissues compared with non-cancer tissues (Supplementary Fig. 2h). Similarly, the analysis of data from two published studies $^{31,32}$ showed that SCN4B expression levels were downregulated in lung cancer compared with normal lung tissues (Supplementary Fig. 3a,b) and our immunohistochemical analyses in lung cancer tissue microarrays also identified a tendency for decreased protein expression in highgrade primary lung tumours and metastases (Supplementary Fig. 3c,d). SCN $4 B$ expression was also down-regulated in prostate, colon and rectal cancers compared with normal tissues (Supplementary Fig. 3e,g). This suggests that $S C N 4 B / \beta 4$ is normally expressed in normal epithelial cells (also confirmed by immunohistochemical analyses of normal oesophagus (Supplementary Fig. 4) and that its loss of expression is associated with a gain in invasive properties by cancer cells and an aggressive progression of epithelial tumours. Correlatively, we found that $S C N 4 B$ expression was higher in non-cancer epithelial mammary MCF-10A compared with several breast cancer cell lines such as MCF-7, MDA-MB-468, MDA-MB-435s and MDA-MB-231 (Fig. 3a,b). Particularly, the expression level of $S C N 4 B$ was low in the highly invasive and metastatic MDA-MB-231 breast cancer cells, known to express functional $\mathrm{Na}_{\mathrm{V}} 1.5$ (ref. 22). SCN $4 B$ mRNA (Fig. 3c) and protein (Fig. 3d) were expressed in MDA-MB-231 cells genetically modified with the luciferase gene (MDA-MB-231-Luc cells). $S C N 1 B / \beta 1$ and $S C N 2 B / \beta 2$ were also expressed, but not $S C N 3 B / \beta 3$. The lack of expression of $S C N 3 B / \beta 3$ was further demonstrated in conventional PCR using two different couples of primers (Supplementary Fig. 5a), thus confirming previously published results obtained with wild-type cells ${ }^{24,33}$. Transient silencing of $S C N x B$ genes using specific small-interfering RNA (siRNA: siSCN1B, siSCN2B or siSCN4B) was responsible for significant $(65-80 \%)$ decreases in protein levels $48 \mathrm{~h}$ after transfection, as compared with a control null-target siRNA (siCTL) (Fig. 3e). The downregulation of one of the $S C N x B$ gene had no effect on the mRNA expression of the others, suggesting the absence of compensation between $S C N x B / \beta$ subunits in these conditions (Supplementary Fig. 5b). While reduced expression of either $S C N 1 B / \beta 1$ or $S C N 2 B / \beta 2$ decreased cancer cell invasiveness through Matrigel-coated invasion chambers by $42.8 \pm 6.6 \%$ $(n=8)$ and $51.7 \pm 0.3 \% \quad(n=8) \quad$ (mean \pm s.e.m. (number of independent experiments)), respectively, inhibition of $S C N 4 B$ expression enhanced invasiveness by $62.4 \pm 12.2 \% \quad(n=8)$ (Fig. 3f,g). We also analysed the consequences of knockingdown the expression of SCN4B on MDA-MB-231-Luc invasiveness in vivo using the zebrafish model of micrometastasis ${ }^{34,35}$. Sixty-one per cent of zebrafish embryos injected with siCTL cells had their organs colonized. This number was increased to approximately $87 \%$ of the embryos presenting micrometastases when injected with siSCN $4 B$ cells, resulting in an increase in the zebrafish colonization index by $1.41 \pm 0.08$ fold $(n=3)$ (Fig. 3h,i). These quantifications were performed $72 \mathrm{~h}$ after siRNA transfection, a time for which $S C N 4 B$ downregulation was still efficient (Supplementary Fig. 6a).

Independence of pore-forming $\mathrm{Na}_{\mathbf{v}}$ subunits. Breast cancer cell invasiveness has been demonstrated to be strongly regulated by the activity of the pore-forming $\mathrm{Na}_{\mathrm{V}} 1.5$ (refs 19,20,24). Therefore, we initially hypothesized that loss of $S C N 4 B$ expression would increase $\mathrm{Na}_{\mathrm{V}} 1.5$ activity in highly aggressive cancer cells. To test this hypothesis, we generated MDA-MB-231-Luc-derived cell lines stably expressing a null-target small hairpin RNA (shCTL cells), or expressing shRNAs targeting either the expression of SCN5A gene encoding for $\mathrm{Na}_{\mathrm{V}} 1.5$ (shSCN5A cells, in which the expression of the $S C N 4 B$ gene is not changed) as previously described $^{22}$ or targeting SCN $4 B$ transcripts (shSCN4B cells). The use of $\operatorname{shSCN} 4 B$ resulted in $81.1 \pm 0.2 \%(n=37)$ decrease in mRNA levels (Supplementary Fig. 6b) with no effect on the expression of the other $S C N x B$ subunits (Supplementary Fig. 6d,e). The three cell lines generated displayed identical viability and growth properties (Supplementary Fig. 6c). In shCTL cells, $I_{\mathrm{Na}}$ is known to be generated by the sole $\mathrm{Na}_{\mathrm{V}} 1.5$ isoform which, while commonly referred to as tetrodotoxin (TTX)-resistant, can almost completely be inhibited by $30 \mu \mathrm{M}$ $\mathrm{TTX}^{22,36}$. Similarly to already reported results ${ }^{24,37}$, the inhibition of $\mathrm{Na}_{\mathrm{V}} 1.5$ sodium currents in shCTL cells using $30 \mu \mathrm{M}$ TTX reduced invasiveness by $45.3 \pm 4.3 \% \quad(n=8)$, similar to the reduction in invasiveness $(43.4 \pm 5.1 \%, n=6)$ in shSCN5A cells, not expressing $\mathrm{Na}_{V} 1.5$ and which were no longer sensitive to the addition of TTX (Fig. 4a). Knocking-down the expression of the $S C N 4 B$ gene with different interfering RNA sequences resulted in similar potentiations of aggressiveness (shSCN4B, Fig. 4a and siSCN4B; Fig. $3 e, f)$. ShSCN4B cell invasiveness was $281.8 \pm 16.2 \%$ $(n=16)$ higher than that of shCTL cells. The treatment of shSCN4B cells with $30 \mu \mathrm{M}$ TTX, a concentration that inhibits all $\mathrm{Na}_{V}$ channels, with the exception of the very TTX-resistant $\mathrm{Na}_{V} 1.8$, significantly reduce their invasiveness (Fig. 4a). To assess a possible independence from $\mathrm{Na}_{\mathrm{V}} 1.5$ in the increased invasiveness mediated by the loss of $S C N 4 B$ expression, we silenced SCN5A expression in shSCN4B cells. This significantly reduced cancer cell invasiveness, which was still $184.3 \pm 27.0 \%$ $(n=12)$ of shCTL cells (Fig. $4 \mathrm{~b})$. We then transiently inhibited the expression of $S C N 4 B$ using siSCN4B siRNA in shSCN5A cells, which no longer express $\mathrm{Na}_{\mathrm{V}}$ 1.5. These cells were also treated or not with (i) $3 \mu \mathrm{M}$ TTX which inhibits all TTX-sensitive channels ( $\mathrm{Na}_{\mathrm{V}} 1.1-1.4$ and $\left.\mathrm{Na}_{\mathrm{V}} 1.6-1.7\right)$ or (ii) $30 \mu \mathrm{M}$ TTX to also inhibit $\mathrm{Na}_{V} 1.5$ and $\mathrm{Na}_{V} 1.9$ TTX-resistant channels, or (iii) with $30 \mathrm{nM}$ of the specific $\mathrm{Na}_{\mathrm{V}} 1.8$ inhibitor $\mathrm{A} 803467^{38}$. As shown in Fig. 4c, silencing SCN4B expression with siSCN4B in shSCN5A cells increased invasiveness $(+251.7 \pm 20.8 \%, n=6)$ similarly to what was observed with $\operatorname{shSCN} 4 B$ cells expressing $\mathrm{Na}_{\mathrm{V}} 1.5$ (Fig. 4a). Furthermore, neither TTX nor A803467 reduced invasiveness of shSCN5A cells transfected with siCTL or siSCN4B (Fig. 4c). Altogether, these data clearly demonstrate that the increased invasiveness of $S C N 4 B$ gene-suppressed cells was not a consequence of the upregulation of $\mathrm{Na}_{\mathrm{V}} 1.5$ or of any other $\mathrm{Na}_{V}$. We also assessed the effect of knocking-down the expression of $S C N 4 B$, using siRNA, on the invasive properties of cancer cell lines, such as the non-small-cell human lung cancer H460 or the human prostate cancer PC3 cell lines, known to express functional $\mathrm{Na}_{\mathrm{V}}\left(\mathrm{Na}_{\mathrm{V}}^{+}\right)$contributing to mesenchymal invasion. In addition, we used cancer cell lines that do not express $\mathrm{Na}_{\mathrm{V}}$ $\left(\mathrm{Na}_{\bar{V}}\right)$ such as the less invasive human breast MDA-MB-468 and the non-small-cell lung A549 cancer cell lines ${ }^{21,39,40}$. In all cancer cell lines tested, showing similar levels of $S C N 4 B$ expression (Supplementary Fig. 5d), transfection of siSCN $4 B$ significantly increased the invasiveness, from $23.7 \pm 8.3 \%(n=3)$ increase for PC3 cells up to $60.9 \pm 9.5 \%(n=12)$ increase in A549 cells (Fig. $4 \mathrm{~d}$ ), confirming that $S C N 4 B / \beta 4$ loss potentiates invasiveness independently of the pore-forming $\mathrm{Na}_{\mathrm{V}}$ subunit.

Because $\mathrm{Na}_{\mathrm{V}} 1.5$ has been reported as an important regulator of mesenchymal invasion in breast cancer cells through the potentiation of NHE1-dependent $\mathrm{H}^{+}$efflux and ECM degradation $22,25,26$, we further investigated its regulation in shSCN4B cells. Patch-clamp recordings revealed, contrary to our initial assumptions, that the loss of $S C N 4 B$ expression significantly decreased the maximal peak $I_{\mathrm{Na}}$, as observed in the $I_{\mathrm{Na}}$-voltage relationship (Fig. 5a), suggesting a reduction of channel density at the plasma membrane. This could be due to the reduction of SCN5A expression levels as observed by 
a

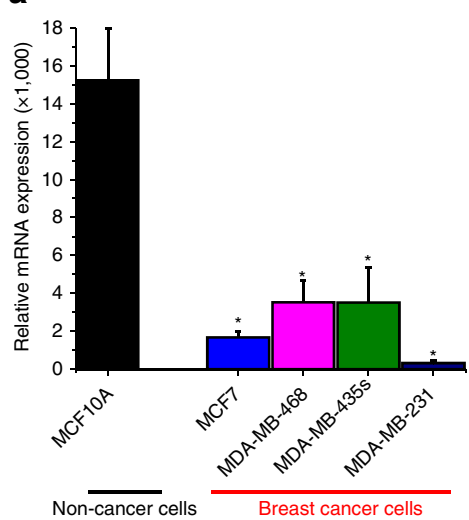

C

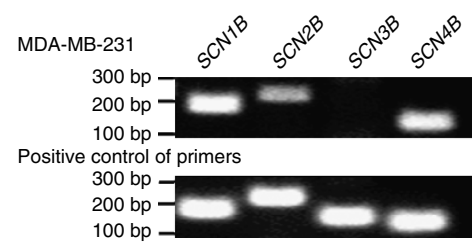

e

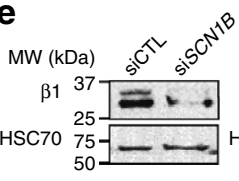

f $\mathrm{SICTL}$
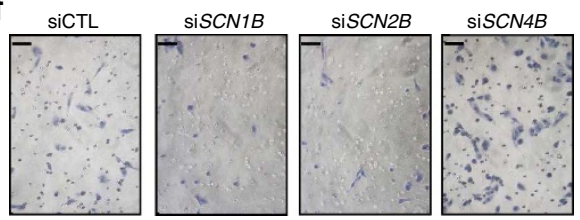

g

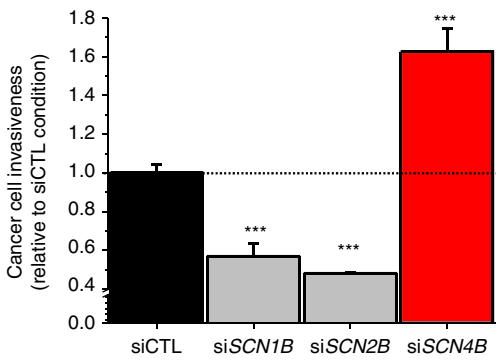

b

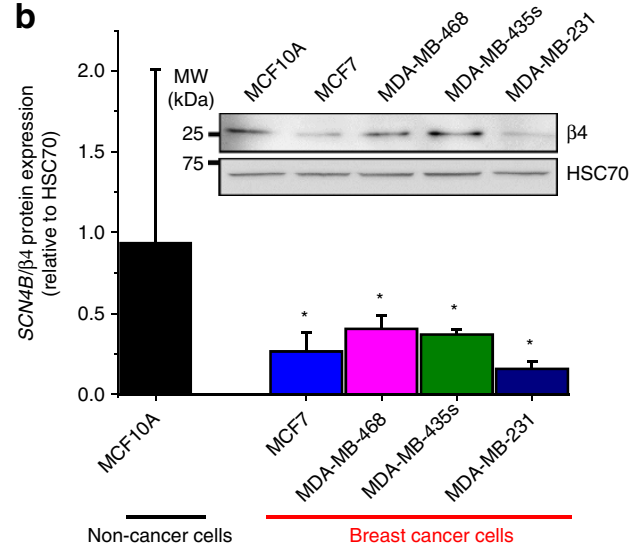

d

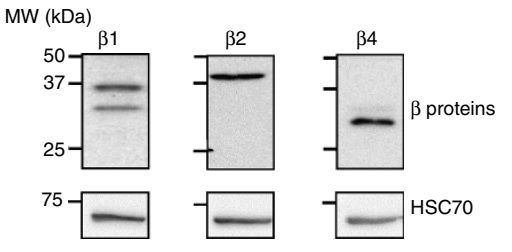

h

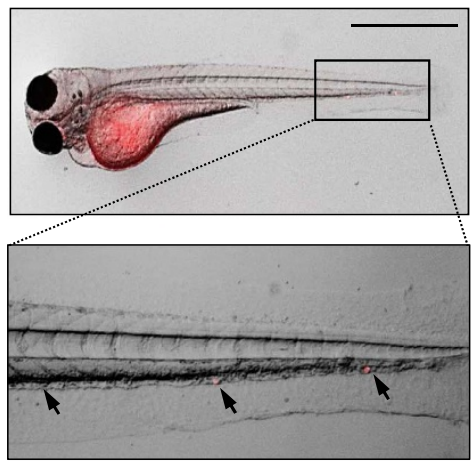

i

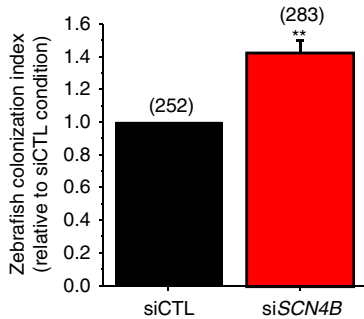

Figure 3 | Expression of the SCN4B/ק4gene in human breast cancer cell lines and contribution to cancer cell invasiveness. (a) The expression of SCN4B gene was studied by RT-qPCR in human mammary epithelial non-cancer MCF-10A and cancer MCF7, MDA-MB-468, MDA-MB-435s and MDA-MB-231 cell lines. Results are expressed as relative to that of HPRT-1 gene $(n=7-12)$ and presented as mean values \pm s.e.m. *, significantly different from MCF-10A at $P<0.05$ (MW). (b) The expression of $S C N 4 B / \beta 4$ protein was studied by densitometric analysis of western blot experiments in same cells as in a. Results are given as the amount of $S C N 4 B / \beta 4$ protein relative to that of $\mathrm{HSC7O}(n=5)$ and presented as mean values \pm s.e.m. *, significantly different from MCF-10A at $P<0.05$ (MW). The image on top shows a representative western blotting experiment. (c) The expression of SCNxB genes was analysed in MDA-MB-231-Luc cells by reverse transcription-PCR. Plasmids encoding human SCNxB genes were used as positive controls for PCR primers.

(d) Representative western blotting experiments showing protein expression for $\beta 1$ (SCN1B), $\beta 2$ (SCN2B) and $\beta 4$ (SCN4B) in MDA-MB-231-Luc cells.

(e) Cells were transfected with scrambled siRNA ( $\mathrm{SiCTL}$ ) or with siRNA directed against the expression of the SCN1B gene (siSCN1B), the SCN2B gene (siSCN2B) or the SCN4B gene (siSCN4B). The efficacy of siRNA transfection was assessed by western blotting experiments $48 \mathrm{~h}$ after transfection. HSC70 was used as a control for sample loading. (f) Representative images of fixed and haematoxylin-stained MDA-MB-231-Luc cells on invasion inserts. Cancer cells were transfected with scrambled siCTL or with specific siRNA. Scale bars, $50 \mu \mathrm{m}$. (g) Summary of cancer cell invasiveness results $(n=8)$ for MDA-MB-231-Luc cells transfected with SiCTL or siSCNxB. Results were expressed relative to siCTL and presented as mean values \pm s.e.m. ${ }^{\star \star \star}$, statistically different from siCTL at $P<0.001$ (Student's $t$-test). (h) Representative image of a zebrafish embryo injected in the yolk sac with MDA-MB-231-Luc cells stained with CM-Dil and showing sites of colonization. Scale bars, $500 \mu \mathrm{m}$. Below is a magnification of the highlighted region containing human cancer cells (see arrows) colonizing organs of the embryo. (i) Zebrafish colonization index of siCTL or siSCN4B cells. Numbers in brackets indicate the number of embryos examined for each condition, from three different experiments. Results are presented as mean values \pm s.e.m. ${ }^{\star \star}$, statistically different from siCTL at $P<0.01$ (Student's $t$-test). 

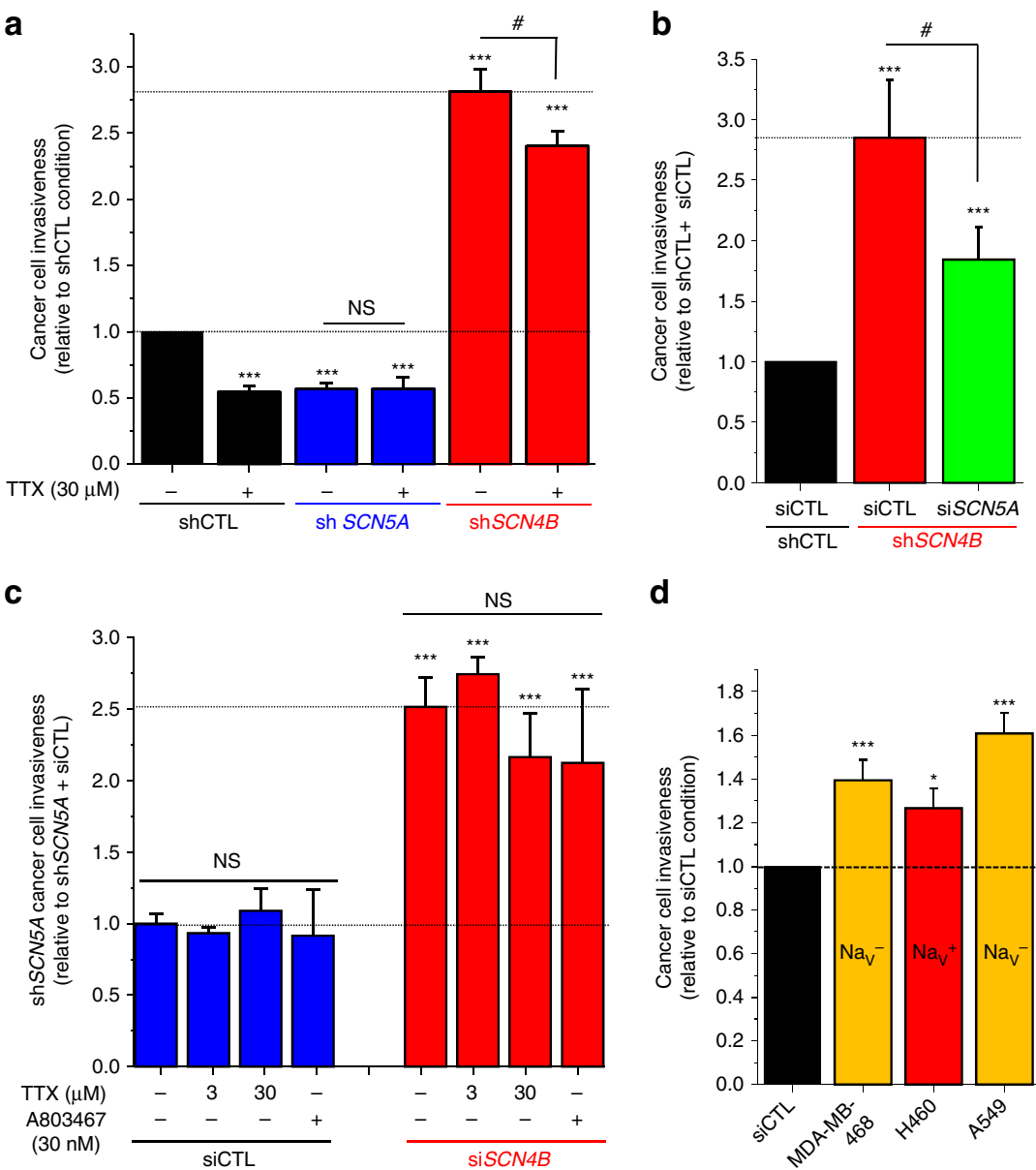

d

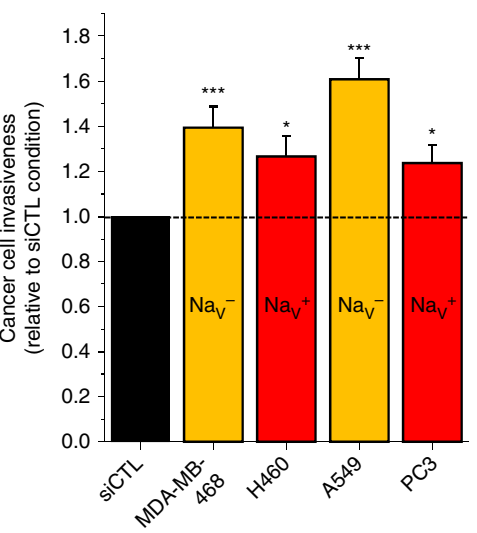

Figure 4 | Loss of SCN4B/ß4 expression promotes human cancer cell invasiveness independently of the pore-forming $\mathbf{N a}_{\mathbf{v}}$ subunit. (a) Cancer cell invasiveness was assessed, using Matrigel-invasion chambers, from MDA-MB-231-Luc cells stably transfected with null-target shRNA (shCTL), SCN5A-targeting shRNA (shSCN5A) or SCN4B-targeting shRNA (shSCN4B), in the absence $(-)$ ) or presence $(+$ ) of $30 \mu \mathrm{M}$ TTX. The results from 8 to 16 independent experiments were expressed relative to control cells transfected with shCTL in the absence of TTX. ${ }^{\star \star \star}$, statistically different from shCTL at $P<0.001$ and \#, statistically different from shSCN4B in the absence of TTX at $P<0.05$. (b) Cancer cell invasiveness was likewise assessed in shCTL or shSCN4B cells, transiently transfected with null-target siRNA (siCTL) or SCN5A-targeting siRNA (siSCN5A). The results from 12 independent experiments were expressed relative to shCTL cells transfected with siCTL. ${ }^{\star \star \star}$, statistically different from the shCTL/siCTL condition at $P<0.001$ and $\#$, statistically different from shSCN4B/siCTL at $P<0.05$. (c) Cancer cell invasiveness was assessed in MDA-MB-231-Luc cells stably expressing the SCN5A-targeting shRNA (shSCN5A), not expressing the Nav1.5 protein, and transiently transfected with null-target siRNA (siCTL) or SCN4B-targeting siRNA (siSCN4B). This effect was assessed in the absence $(-)$ or presence $(+)$ of two TTX concentrations ( 3 or $30 \mu \mathrm{M}$ ), or $30 \mathrm{nM}$ of the Nav1.8 inhibitor A803467. The results from six independent experiments were expressed relative to shSCN5A cells transfected with siCTL, in the absence of any Nav inhibitor. NS stands for no statistical difference and ${ }^{\star \star \star}$ denotes a statistical difference from shSCN5A/siCTL at $P<0.001$. (d) Cancer cell invasiveness was assessed using Matrigelinvasion chambers for MDA-MB-468 breast, $\mathrm{H} 460$ and A549 non-small-cell lung, and PC3 prostate cancer cells transfected with null-target siRNA (siCTL, black bar) or SCN4B-targeting siRNA ( respectively. The results from 3 to 12 independent experiments were presented and are expressed relative to the results obtained with the same cells transfected with siCTL. ${ }^{*}$, different from siCTL at $P<0.05$ and ${ }^{* \star \star}$ at $P<0.001$. Statistics presented in this figure were performed using ANOVA for multiple group comparison $(\mathbf{a}-\mathbf{c})$ or Student's $t$-test $(\mathbf{d})$. All results presented in this figure are mean values \pm s.e.m.

quantitative PCR (qPCR) (Supplementary Fig. 6d). In shSCN4B cells, the $I_{\mathrm{Na}}$ activation-voltage relationship was slightly depolarized as compared with shCTL cells $\left(V_{1 / 2}\right.$-activation were $-37.2 \pm 0.9 \mathrm{mV}(n=22)$ and $-40.1 \pm 1.0 \mathrm{mV}(n=18)$, respectively, $P=0.037$, Student's $t$-test). More importantly, the availability-voltage relationship was also significantly shifted to a more depolarized potential in $\operatorname{sh} S C N 4 B$ cells compared with shCTL cells $\left(V_{1 / 2}\right.$-availability were $-80.6 \pm 1.6 \mathrm{mV}(n=22)$ and $-86.3 \pm 1.6 \mathrm{mV}(n=18)$, respectively, $P=0.016$, Student's $t$-test; Fig. 5b), suggesting that even though there were less $\mathrm{Na}_{V} 1.5$ channels at the plasma membrane, they might be more active at the membrane potential of cancer cells (comprised between -30 and $-40 \mathrm{mV}$ ) through an increased persistent window current. Indeed, while the peak $I_{\mathrm{Na}}$ was reduced in $\operatorname{sh} S C N 4 B$ cells, the persistent $I_{\mathrm{Na}}$ recorded for a membrane depolarization from -100 to $-30 \mathrm{mV}$ was strictly identical (Fig. $5 \mathrm{c}$,d). Therefore, the ratio $I_{\mathrm{Na}}$ persistent $/ I_{\mathrm{Na}}$ peak was significantly enhanced in shSCN4B cells (Fig. 5e). The sensitivity of $I_{\mathrm{Na}}$ to TTX was unchanged in shSCN $4 B$ cells and could almost be fully inhibited by $30 \mu \mathrm{M}$ TTX (inhibited by $85.6 \pm 2.9 \%, n=7-12$; Fig. $5 f$ ). Because the persistent $I_{\mathrm{Na}}$ was similar in shCTL and shSCN4B cells, there was no difference in the efflux of $\mathrm{H}^{+}$in the two cell lines, measured as previously published ${ }^{25}$, by the addition of $130 \mathrm{mM} \mathrm{NaCl}$ in $\mathrm{NH}_{4} \mathrm{Cl}$-pulse-wash-acidified cells in a sodium- 
a

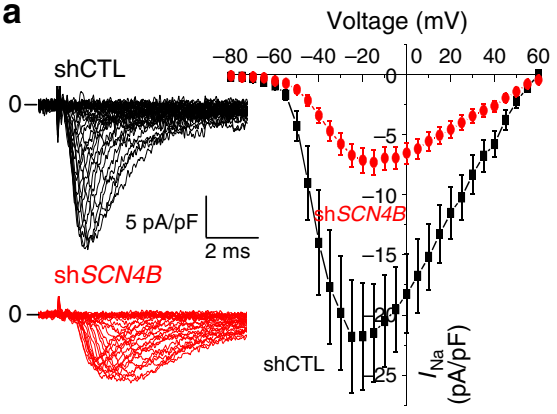

b

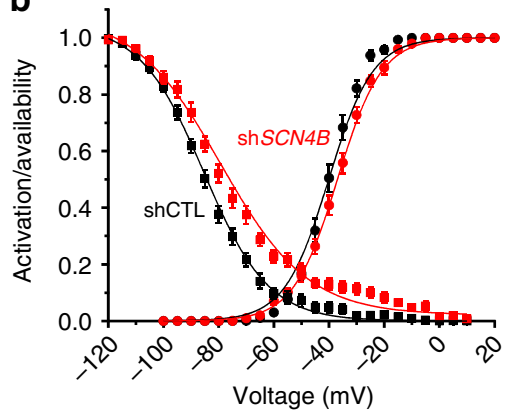

C

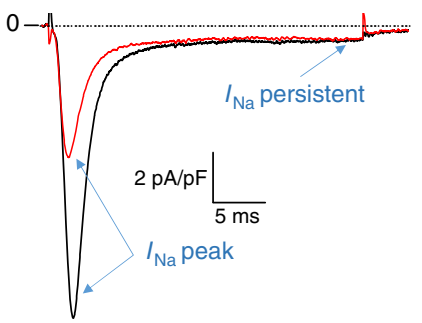

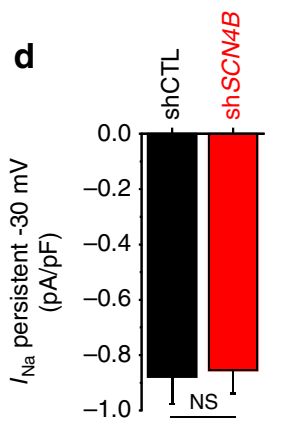

e

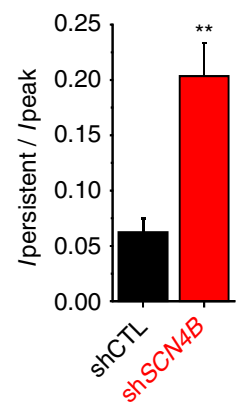

i

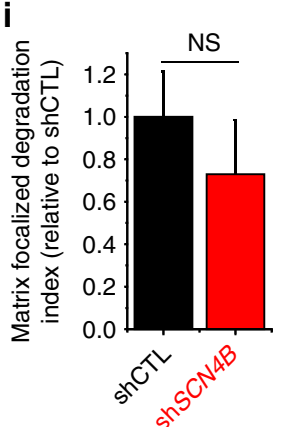

$\mathbf{f}$

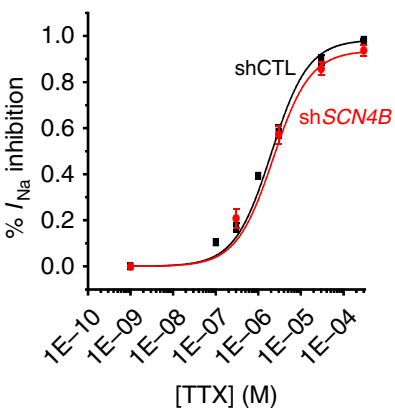

g

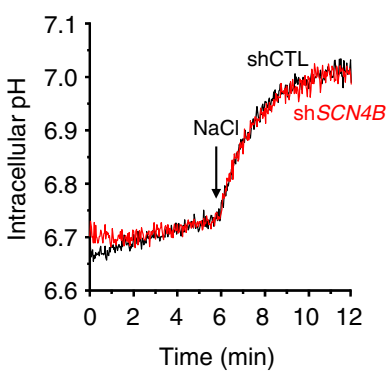

h
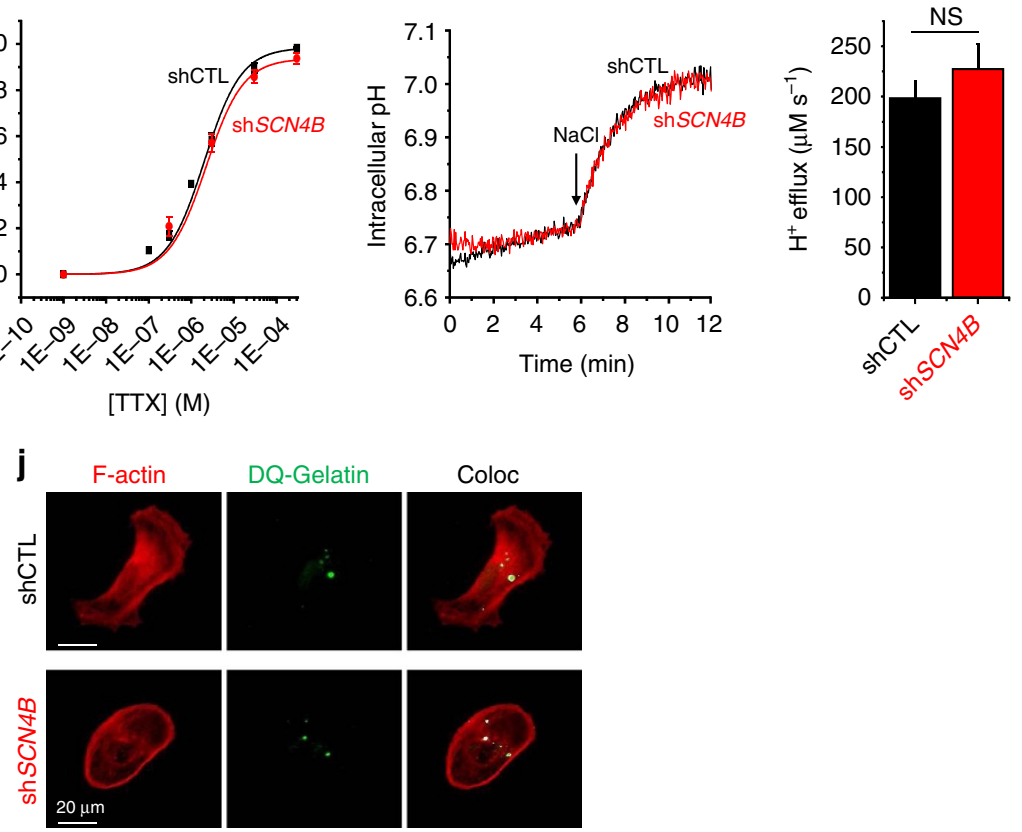

Figure 5 | Loss of SCN4B/ß4 expression maintains Nav1.5-mediated persistent current and dependent extracellular matrix degradation. (a) Sodium current $\left(I_{\mathrm{Na}}\right)$-voltage relationships in shCTL (black squares, $n=18$ ) and in shSCN4B (red circles, $n=22$ ) cells. There was a significant difference at $P<0.001$ between the two conditions in the voltage range between -40 and $+40 \mathrm{mV}$. (b) Activation (filled circles)- and availability (filled squares )voltage relationships in shCTL (black symbols) and shSCN4B (red symbols) cells. (c) $I_{\mathrm{Na}}$ peak and $I_{\mathrm{Na}}$ persistent currents obtained from shCTL (black trace) and shSCN4B (red trace) cells for a membrane depolarization from -100 to $-30 \mathrm{mV}$. (d) Mean values \pm s.e.m. of $I_{\mathrm{Na}}$ persistent currents obtained for a membrane depolarization from -100 to $-30 \mathrm{mV}$ from $18 \mathrm{shCTL}$ and 21 shSCN4B cells. NS, not statistically different. (e) Mean values \pm s.e.m. of $I_{\mathrm{Na}}$ persistent/I $I_{\text {Na }}$ peak currents ratios obtained from $18 \mathrm{shCTL}$ and 21 shSCN4B cells. ${ }^{\star *}$, statistically different from shCTL at $P<0.01$. (f) Dose-response effect of TTX on the inhibition of $I_{\mathrm{Na}}$ peak elicited by a membrane depolarization from -100 to $-5 \mathrm{mV}$ in shCTL (black squares, $n=8-12$ ) and in shSCN4B (red circles, $n=7-12$ ) cells. Data were fitted with the Hill equation and $I_{50}$ values were $2.02 \pm 0.10$ and $2.24 \pm 0.11 \mu M$ for shCTL and shSCN4B cells, respectively. (g) Intracellular $\mathrm{pH}$ measurements using the BCECF-AM probe, in $\mathrm{NH}_{4} \mathrm{Cl}$-acidified shCTL (black trace) and shSCN4B (red trace) cells in the absence of $\mathrm{NaCl}$. $\mathrm{NaCl}\left(130 \mathrm{mM}\right.$ ) was added at the time indicated (arrow). (h) $\mathrm{H}^{+}$efflux measurements after the addition of $\mathrm{NaCl}$ in conditions similar to $\boldsymbol{g}$ $(n=20)$. Results are expressed as mean values \pm s.e.m. NS, no statistical difference. (i) MDA-MB-231 shCTL or shSCN4B cells were cultured on a Matrigel matrix containing DQ-Gelatin. A 'Matrix-Focalized-degradation index' was calculated as being F-actin foci (red labelling, phalloidin-Alexa594) co-localized with focused proteolytic activities (green) ( $n=442$ cells for shCTL and 448 cells and shSCN4B). Results are expressed as mean values \pm s.e.m. NS, no statistical difference. (j) Representative pictures showing matrix degradation areas (green spots) and F-actin foci (red spots). Merging points (coloc), which appear as white pixels, were counted. Numbers of white pixels per cell were normalized to the mean value obtained in shCTL cells. Statistics were performed using Student's t-test.

free solution (Fig. 5g,h). As a consequence, shSCN4B cells demonstrated identical ECM degradative activities as compared with shCTL cells (Fig. 5i,j), and similar levels of co-localization between the phosphorylated form (Y421) of the actin nucleationpromoting factor cortactin, used as a marker of invadopodial structures $^{41}$, and DQ-gelatin degradation (Supplementary Fig. 5c). These results suggested that the invadopodial activity was similar in shCTL and shSCN4B cells.
RhoA-dependent amoeboid cell migration. While cells lacking $S C N 4 B$ expression have the ability to degrade the ECM, the pharmacological inhibition of proteases by GM6001 (MMP inhibitor), leupeptin (cysteine, serine and threonine peptidases inhibitor) or E64 (cysteine cathepsin inhibitor) did not completely prevent the increased invasiveness observed in $\operatorname{sh} S C N 4 B$ as compared with shCTL cells (Fig. 6a). The most potent effect was obtained with GM6001, which reduced $\operatorname{shSCN4B}$ cell 
a

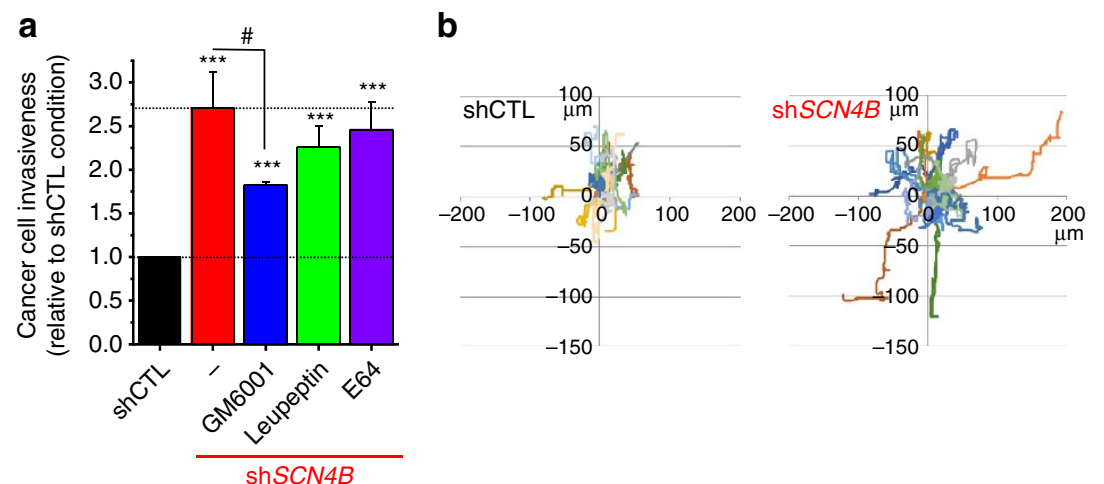

c

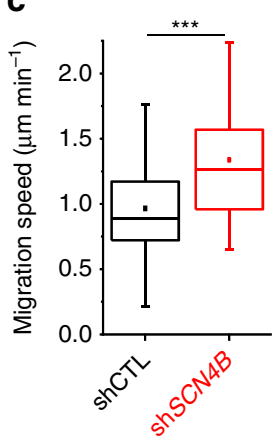

d

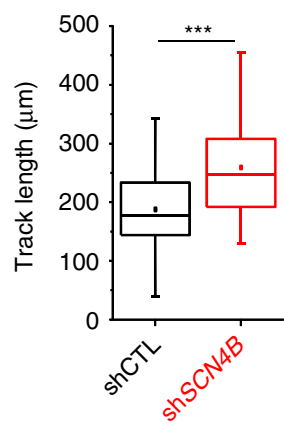

e
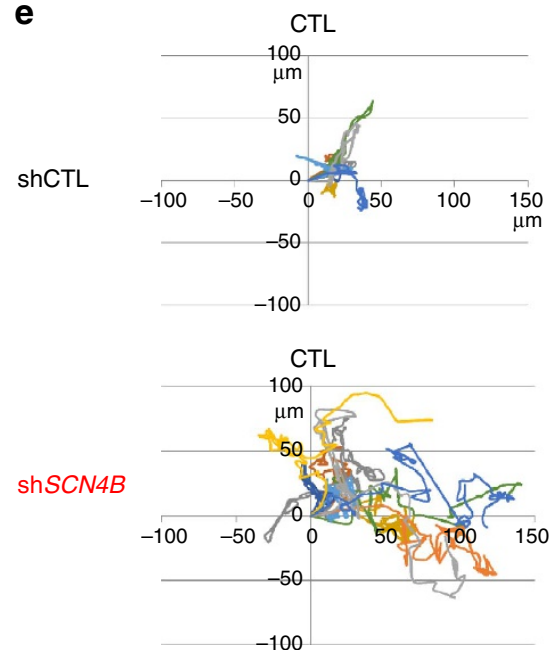

GM6001
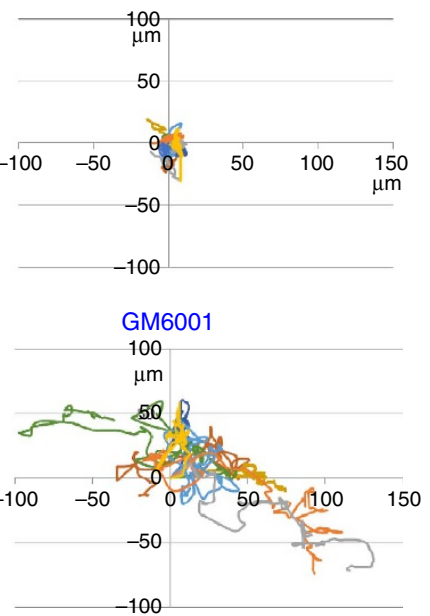

f

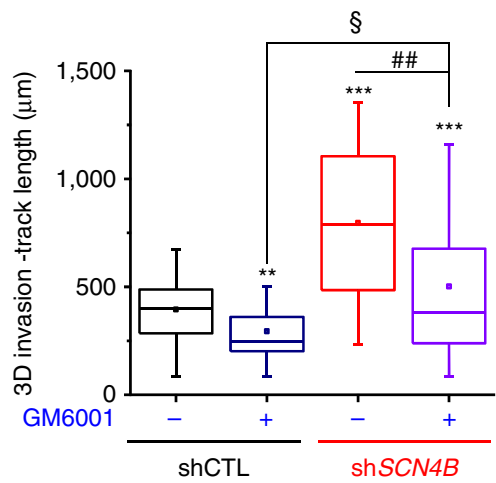

Figure 6 | The loss of SCN4B/ק4 expression promotes human cancer cell migration and invasiveness in two and three dimensions. (a) Cancer cell invasiveness was assessed using Matrigel-invasion chambers from shCTL or shSCN4B MDA-MB-231 cells, in the absence ( - ) or presence of the protease inhibitors GM6001 (10 $\mu \mathrm{M})$, leupeptin $(200 \mu \mathrm{M})$ or $\mathrm{E} 64(100 \mu \mathrm{M})$. Results from three to seven independent experiments are presented and were

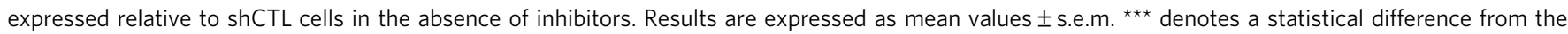
shCTL at $P<0.001$, and \# indicates a statistical difference from shSCN4B at $P<0.05$ (ANOVA). (b) Cancer cell migration of shCTL and shSCN4B cells measured by time-lapse microscopy to track the movement of cells over $180 \mathrm{~min}, 1$ frame per min ( $n=20$ representative cells in each condition). Distances are indicated in $\mu \mathrm{m}$. (c) The speed of migration (in $\mu \mathrm{m} \mathrm{min}^{-1}$ ) was analysed in shCTL and shSCN4B cells from time-lapse experiments and results shown were obtained from 106 and 96 cells, respectively. ${ }^{\star \star \star}$ denotes a statistical difference from the shCTL at $P<0.001$ (MW). (d) The track length of cell migration (in $\mu \mathrm{m}$ ) was analysed over $180 \mathrm{~min}$ in shCTL and shSCN4B cells from time-lapse experiments and results shown were obtained from 106 and 96 cells, respectively. ${ }^{\star \star \star}$ denotes a statistical difference from the shCTL at $P<0.001$ (MW). (e) Three-dimension (3D) invasiveness of shCTL and

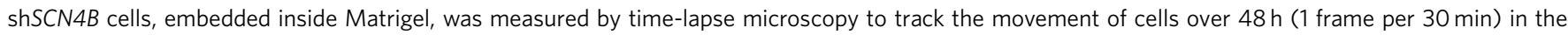
absence (CTL) or presence of the MMP inhibitor GM6001 (10 $\mu \mathrm{M})(n=13$ representative cells in each condition). Distances are indicated in $\mu \mathrm{m}$. (f) The track length of $3 \mathrm{D}$ cell invasiveness (in $\mu \mathrm{m}$ ) was analysed over $48 \mathrm{~h}$ in shCTL and shSCN4B cells from time-lapse experiments and results shown were obtained from 30 cells in each condition. ${ }^{\star \star}$ and ${ }^{\star \star \star}$ denote statistical difference from the shCTL, CTL condition at $P<0.01$ and $P<0.001$, respectively. \#\# denotes a statistical difference from the shSCN4B, CTL condition at $P=0.002$. $§$ denotes a statistical difference from the shCTL, GM6001 condition at $P=0.038$ (Dunn's test). (c,d and f) Box plots indicate the first quartile, the median and the third quartile; whiskers indicate minimum and maximum values; squares show the means. Error bars encompass $95 \%$ of data samples.

invasiveness by about $32 \%$. This suggested that the enhancement of invasiveness was not solely due to an increase in ECM proteolysis, thus prompting us to analyse the migratory abilities of cell lines using time-lapse cell tracking experiments (Fig. 6b). As expected, the loss of SCN4B expression significantly increased the migration speed (medians were $0.889 \mu \mathrm{m} \mathrm{min}^{-1}$ for shCTL $(n=106)$ and $1.265 \mu \mathrm{mmin}^{-1}$ for shSCN4B cells $(n=96)$, $P<0.001$, Mann-Whitney rank sum test; Fig. $6 \mathrm{c}$ ), as well as the track length after $3 \mathrm{~h}$ measurements (medians were $177.76 \mu \mathrm{m}$ for shCTL $(n=106)$ and $246.73 \mu \mathrm{m}$ for shSCN4B cells $(n=96)$, $P<0.001$, Mann-Whitney rank sum test; Fig. 6d), but with no change in net displacement (Supplementary Fig. 6f). This increase in migration velocity was evocative of a transition towards the amoeboid invasiveness, which is better visualized in three-dimensional (3D) matrices. To study this property more adequately shCTL and shSCN4B cells were seeded into a $3 \mathrm{D}$ matrix composed of Matrigel and invasive abilities were analysed, in the absence or presence of GM6001, using time-lapse singlecell tracking over $48 \mathrm{~h}$ (Fig. 6e). The loss of $S C N 4 B$ expression significantly increased the $3 \mathrm{D}$ track length travelled by cells over $48 \mathrm{~h}$ (medians were $399.39 \mu \mathrm{m}$ for shCTL and $789.11 \mu \mathrm{m}$ for shSCN4B, $P<0.001$, Mann-Whitney rank sum test; Fig. 6f). This increase in $3 \mathrm{D}$ invasion could not be attributed to the increase in ECM degradative activity, since $\operatorname{sh} S C N 4 B$ invasion was significantly higher than in shCTL cells in the presence of GM6001 (medians were $246.76 \mu \mathrm{m}$ for shCTL + GM6001 $(n=30)$ and $379.87 \mu \mathrm{m}$ for $\operatorname{shSCN} 4 B+\mathrm{GM} 6001 \quad(n=30)$, $P=0.038$, Mann-Whitney rank sum test; Fig. 6f). The amoeboid phenotype is generally characterized by a rounded morphology, the presence of blebs at the cell surface and a relative 
independence of the interaction with the substratum revealed by a decreased number of filopodial structures. Consistent with this, shSCN4B cells demonstrated striking changes in morphology with a higher circularity index $(0.48 \pm 0.02 \quad(n=88)$ versus $0.34 \pm 0.02 \quad(n=88)$ in $\operatorname{shSCN} 4 B$ and shCTL, respectively, $P<0.001$, Students' $t$-test; Fig. 7a). Using scanning electron microscopy (SEM), we also noticed a decreased number of filopodia-like structures per cell (medians were $19.0 \quad(n=60)$ versus $44.5(n=66)$ in shSCN4B and shCTL, respectively, $P<0.001$, Mann-Whitney rank sum test; Fig. 7b,c), and an increase in the number of blebs per cell (medians were $100.5(n=82)$ versus $27.5(n=82)$ in shSCN4B and shCTL, respectively, $P<0.001$ Mann-Whitney rank sum test; Fig. $7 \mathrm{~b}-\mathrm{d}$ ). These blebs were relatively small with diameters between 0.5 and $0.7 \mu \mathrm{m}$ (Fig. 7b). To confirm that the filopodia-like structures observed by SEM were real filopodia, and not retraction fibres, a

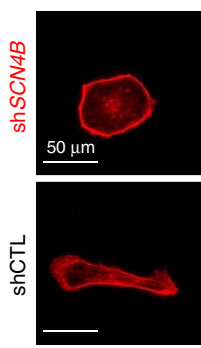

b

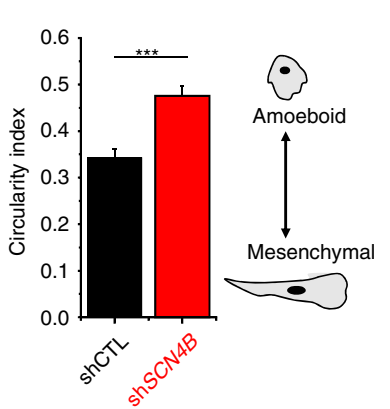

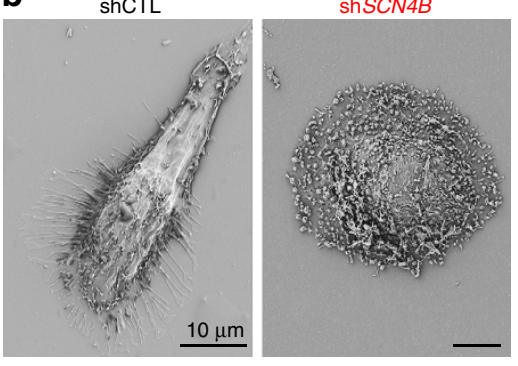

C

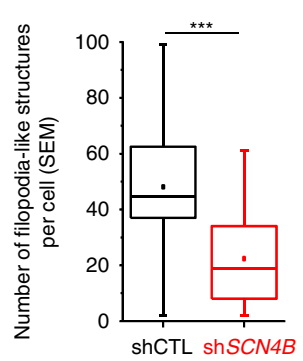

d

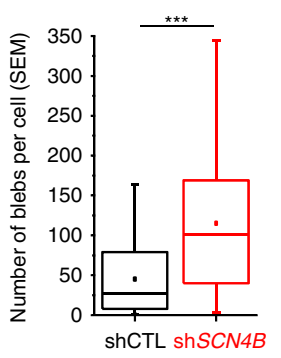

e

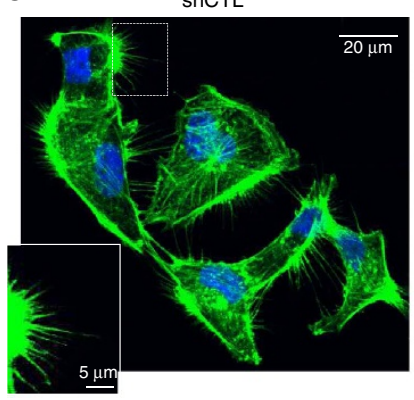

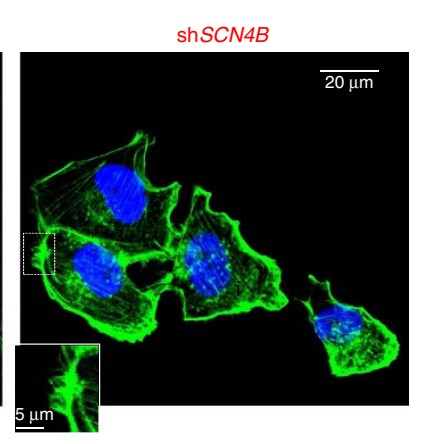

$\mathbf{f}$

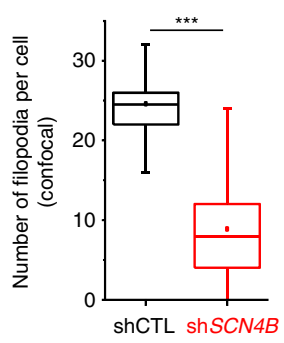

g

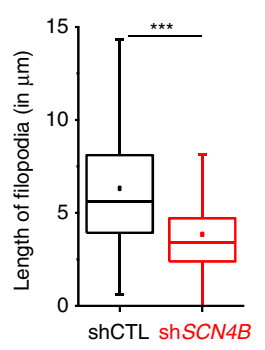

h

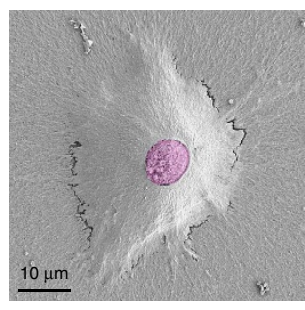

i

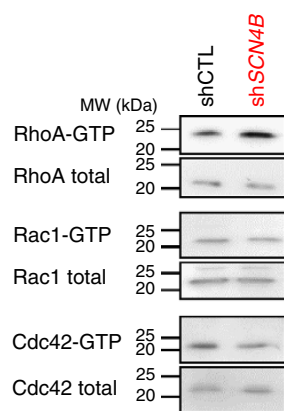

j

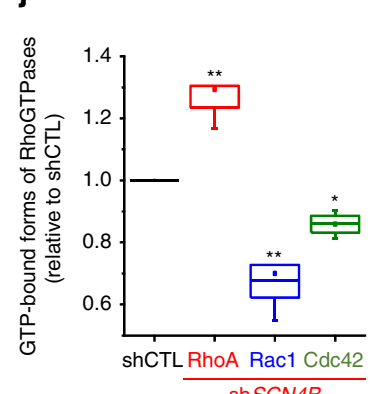

$\mathbf{k}$
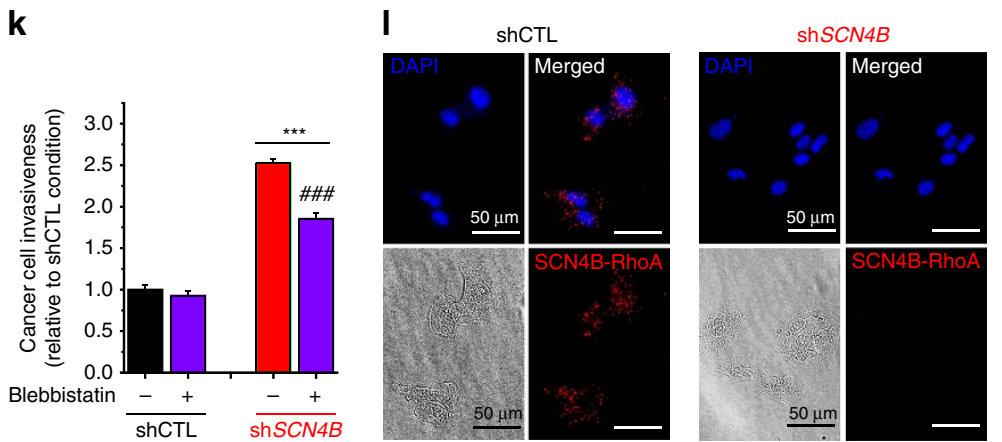

Figure 7 | The loss of SCN4B/B4 expression promotes RhoA-dependent amoeboid cell transition and migration. (a) F-actin was stained with phalloidin-AlexaFluor594 in shCTL and shSCN4B cells and a cell circularity index was calculated ( $n=88$ cells per condition). Results are expressed as mean values \pm s.e.m. ${ }^{\star \star \star} P<0.001$ from shCTL (Student's $t$-test). (b) Representative SEM micrographs of shCTL and shSCN4B cells. Scale bars, $10 \mu \mathrm{m}$. (c) Number of filopodia-like structures per cell, counted from SEM pictures in shCTL and shSCN4B cells $\left(n=60\right.$ and 66 cells, respectively). ${ }^{\star \star \star} P<0.001$ from shCTL (MW). (d) Number of blebs per cell, counted from SEM micrographs in shCTL and shSCN4B cells ( $n=82$ cells per condition). ${ }^{\star \star \star} P<0.001$ from shCTL (MW). (e) Representative confocal micrographs of shCTL and shSCN4B cells for which F-actin was stained with phalloidin-AlexaFluor488 (green) and nuclei with DAPI (blue), scale bar $20 \mu \mathrm{m}$. For enlargements images, scale bars are $5 \mu \mathrm{m}$. (f) Number of filopodia per cell, counted from confocal micrographs in shCTL and shSCN4B cells ( $n=46$ and 66 cells, respectively). ${ }^{\star \star \star} P<0.001$ from shCTL (MW). (g) Length of filopodia, measured from confocal micrographs, in shCTL and shSCN4B cells ( $n=1,070$ and 593 filopodia, respectively). ${ }^{\star \star \star}$, statistically different from shCTL at $P<0.001$ (MW). (h) SEM observations of shSCN4B cell invasion $24 \mathrm{~h}$ after cells were seeded on a layer of Matrigel $\left(4 \mathrm{mg} \mathrm{ml}{ }^{-1}\right)$. The coloured structure is the tip of the cell still observable above the Matrigel layer, while penetrating inside the matrix. Scale bar, $10 \mu \mathrm{m}$. (i) Western blots showing total and active GTP-bound forms of RhoA, Rac1 and Cdc42, pulled down by GST-RBD in shCTL and shSCN4B cells. (j) Quantification of GTP-bound RhoGTPases (active), normalized to total protein level, and expressed relatively to that of shCTL $(n=5)$. ${ }^{\star}$, statistically different from shCTL at $P<0.01$ and ${ }^{*}$ at $P<0.05(M W)$. (k) shCTL or shSCN4B cancer cell invasiveness, in the absence $(-)$ or presence of blebbistatin $(50 \mu \mathrm{M})(n=3)$. Results are expressed as mean values \pm s.e.m.

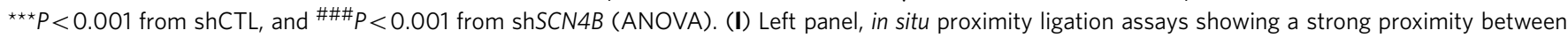
$S C N 4 B / \beta 4$ proteins and RhoA in shCTL cells (red dots, left panel) and the absence of any proximity signal in shSCN4B cells (right panel). Scale bars, $50 \mu \mathrm{m}$. $(\mathbf{c}, \mathbf{d}, \mathbf{f}, \mathbf{g}, \mathbf{j})$ Box plots indicate the first quartile, the median and the third quartile; whiskers indicate minimum and maximum values; squares show the means. Error bars encompass $95 \%$ of data samples. 
we also stained F-actin and performed confocal imaging (Fig. 7e). In agreement with results previously obtained in SEM, shSCN4B cells displayed less filopodia than shCTL cells (median were 8 ( $n=66$ cells) versus $24.5 \quad(n=46$ cells $)$ filopodia/cells for shSCN4B and shCTL, respectively, $P<0.001$, Mann-Whitney rank sum test; Fig. 7e,f). Furthermore, filopodia in shSCN4B cells were smaller than in shCTL cells (median length were 3.43 versus $5.61 \mu \mathrm{m}$ in shSCN4B and shCTL, respectively, $P<0.001$, Mann-Whitney rank sum test; Fig. 7e-g). The morphological changes observed in shSCN4B cells might result from a transition towards an amoeboid phenotype that could confer cancer cells the ability to squeeze and migrate through small gaps of the ECM. Using SEM, we confirmed that shSCN4B cells demonstrated the ability to migrate through Matrigel, probably after they opened a narrow interstice by focalized degradation (Fig. 7h, Supplementary Fig. 7). The interconversions between mesenchymal and amoeboid modes of invasion are known to be orchestrated by RhoGTPases and the amoeboid movement mainly relies on the RhoA-ROCK-pMLCII signalling pathway. We therefore assessed the proportion of active (GTP-bound) RhoGTPases in shCTL and shSCN4B cells by pull-down assays (Fig. 7i) and found a significant increase in RhoA concomitant with decreases in Racl and Cdc-42 activities (Fig. 7j). Furthermore, the inhibition of myosin II with blebbistatin ${ }^{42}$ significantly reduced shSCN4B cancer cell invasiveness by approximately $27 \%$, while it had no effect on shCTL cell invasiveness (Fig. 7k). Interestingly, proximity ligation assays indicated a close association of the $S C N 4 B / \beta 4$ protein and RhoA in shCTL cells while no signal was observed in shSCN4B cells (Fig. 7l). Because the reduced expression of $S C N 4 B$ increases cancer cell aggressiveness, we investigated whether its stable experimental overexpression (oeSCN4B) could have opposite effects. The overexpression of $S C N 4 B$ gene, confirmed by qPCR and western blotting experiments (Supplementary Fig. 8a,b), significantly reduced cancer cell invasiveness by $51.6 \pm 6.8 \%$ $(n=6)$ in oeSCN4B as compared with control cells and by about $82 \%$ as compared with shSCN4B cells (Fig. 8a). To further investigate the regulation of $\mathrm{Na}_{\mathrm{V}}$ activity and $\mathrm{Na}_{\mathrm{V}}$-dependent invasiveness, we performed invasion experiments in the presence or absence of $30 \mu \mathrm{M}$ TTX. While TTX reduced the invasion of control (oeCTL) cells to an extent similar to that found in wild-type or shCTL cells (i.e., a reduction by $30.7 \pm 4.0 \%, n=6$ ), it had no further effect on reducing the invasive properties of oeSCN4B cells (Fig. 8b). Overexpressing SCN4B did not affect cancer cell growth and viability (Supplementary Fig. 8c). These results suggested that overexpression of $S C N 4 B$ not only reduced the invasiveness via the $S C N 4 B / \beta 4$ protein-dependent signalling pathway but also inhibited the $\mathrm{Na}_{\mathrm{V}}$-dependent mesenchymal invasion. To test this hypothesis, we analysed $I_{\mathrm{Na}}$ in oeSCN4B cells. The maximal peak $I_{\mathrm{Na}}$ was higher in oeSCN4B cells as compared with oeCTL or shCTL cells, while the sensitivity to TTX remained unchanged (Fig. 8c and Supplementary Fig. 8d). In oeSCN4B cells, the $I_{\mathrm{Na}}$ activation-voltage relationship was not different from that of oeCTL cells $\left(V_{1 / 2}\right.$-activation were $-42.8 \pm 0.4 \mathrm{mV}(n=43)$ and $-41.9 \pm 0.8 \mathrm{mV}(n=15)$, respectively; Fig. $8 \mathrm{~d}$ ) and the availability-voltage relationship was slightly, but not significantly, shifted towards hyperpolarized values in oeSCN $4 B$ as compared with those obtained with oeCTL cells $\left(V_{1 / 2}\right.$-availability were $-88.6 \pm 1.0$ and $-86.7 \pm 0.5 \mathrm{mV}$, respectively, $P=0.459$, Mann-Whitney rank sum test; Fig. $8 \mathrm{~d}$ ). This result was not statistically significant when compared with the $V_{1 / 2}$-availability in shCTL cells $(-86.3 \pm 1.6 \mathrm{mV}$, $P=0.146$, Mann-Whitney rank sum test), but was significant when compared with the $V_{1 / 2}$-availability in shSCN4B cells $(-80.6 \pm 1.6 \mathrm{mV}, P<0.001$, Mann-Whitney rank sum test). We however measured a decrease in the persistent $I_{\mathrm{Na}}$ current
(Fig. 8e) and in $I_{\mathrm{Na}}$ persistent/peak ratio in oeSCN4B cells as compared with oeCTL (Fig. 8f) and a significant reduction of the focalized Matrigel degradation (Fig. 8g), suggesting that overexpression of $S C N 4 B / \beta 4$ protein slightly reduced the persistent window current and its associated ECM proteolytic (mesenchymal) activity in cancer cells. This observation was also accompanied with reductions in the cell circularity index (from $0.49 \pm 0.02(n=73)$ to $0.38 \pm 0.02(n=73)$ in oeCTL and oeSCN4B, respectively, $P<0.001$, Student's $t$-test; Fig. $8 \mathrm{~h}$ and Supplementary Fig. 9a), in the migration speed (medians are $0.983 \mu \mathrm{m} \mathrm{min}^{-1}$ for oeCTL $(n=47)$ and $0.520 \mu \mathrm{m} \mathrm{min}^{-1}$ for oeSCN4B cells $(n=47), P<0.001$, Mann-Whitney rank sum test; Fig. 7i) and in RhoA activity (Fig. 8j,k). Overall, these results indicate that $S C N 4 B / \beta 4$ protein reduces mesenchymal invasion and prevents amoeboid migration by reducing $\mathrm{Na}_{\mathrm{V}}$ and RhoA activities, respectively.

$S C N x B / \beta$ proteins, initially characterized as being 'auxiliary' subunits of $\mathrm{Na}_{V}$, have been proposed to also act as cell adhesion molecules (CAMs) via their immunoglobulin-like extracellular domain $^{14}$. To investigate the participation of $S C N 4 B / \beta 4$ protein domains in the phenotypical changes observed, we constructed different variants of the protein intended to be overexpressed in shSCN4B cells. For this purpose, the nucleotide sequence was mutated so that the transcripts would not to be targeted by the shRNA. Eight nucleotides were substituted without altering the amino acid sequence. The 'full-length' sequence allowed the expression of a wild-type $\beta 4$ protein in shSCN $4 B$ cells. We also constructed two truncated variants: an N-terminus-truncated protein (from residue M1 to T161), called ' $\Delta \mathrm{N}$-ter', containing the transmembrane and $\mathrm{C}$-terminus intracellular domains of the $S C N 4 B / \beta 4$ protein but completely devoid of the Ig-like extracellular domain, and a $S C N 4 B / \beta 4$ protein truncated in the $\mathrm{C}$-terminus region, from residue $\mathrm{K} 185$, and identified as being ' $\Delta$ C-ter' (Fig. 9a). The $\Delta \mathrm{C}$-ter construct contained the same eight substituted nucleotides with conservation of the amino acid sequence so that it could be expressed in $\operatorname{sh} S C N 4 B$ cells. The protein expression level of these variants at the plasma membrane was similar (Supplementary Fig. 9b). The reintroduction of the full-length $S C N 4 B / \beta 4$ protein significantly reduced cancer cell invasiveness as compared with the empty vector (pSec), and as such, performed as an effective rescue. Interestingly, the $\Delta \mathrm{C}$-ter variant, which possessed the extracellular domain, was completely ineffective, whereas the $\Delta \mathrm{N}$-ter variant reduced cell invasiveness to the same extent as the full-length protein (Fig. 9b). The invasiveness of shSCN4B cells overexpressing the $\Delta \mathrm{N}$-ter variant or the full-length protein was still superior to the one of shCTL cells by about $50 \%$. In agreement with these results, only the full-length and the $\Delta \mathrm{N}$-ter proteins reduced the speed of migration and RhoA activity (Fig. 9c,d) in $\operatorname{sh} S C N 4 B$ cells, therefore demonstrating that the intracellular C-terminus of the $S C N 4 B / \beta 4$ protein, and not the extracellular Ig-like domain, is needed to inhibit invasiveness in breast cancer cells.

Tumour progression. Two important steps in tumour progression are the entry of cancer cells into the vasculature and their dissemination into the general circulation before colonization of secondary organs. This progression requires cellular intravasation/extravasation abilities that can be assessed in vitro using transendothelial invasion (with an initial migration through the ECM, before crossing over the endothelium) and migration protocols, respectively. In both experiments, the downregulation of $S C N 4 B$ importantly potentiated the capacity of cancer cells to migrate through a monolayer of endothelial cells, after having invaded (invasion), or not (migration), a layer of matrigel, as compared with shCTL or oeSCN4B cells (Fig. 10a,b). 


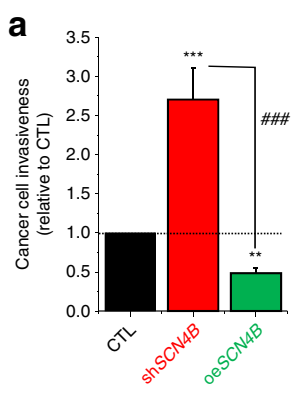

b

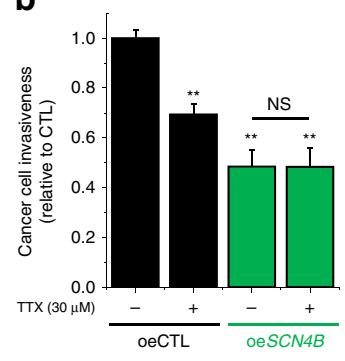

C

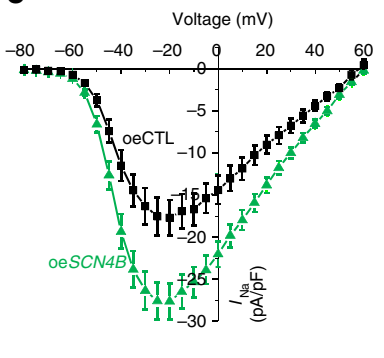

d
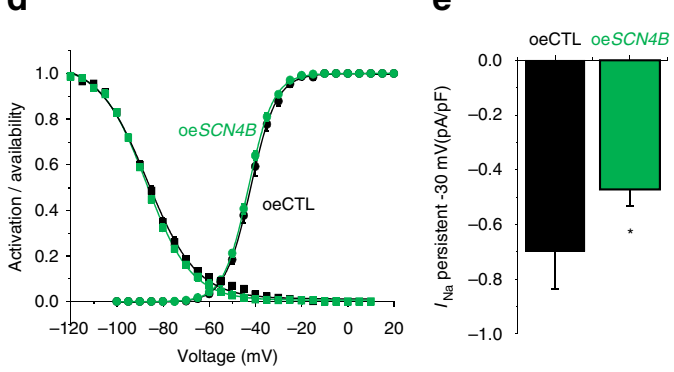
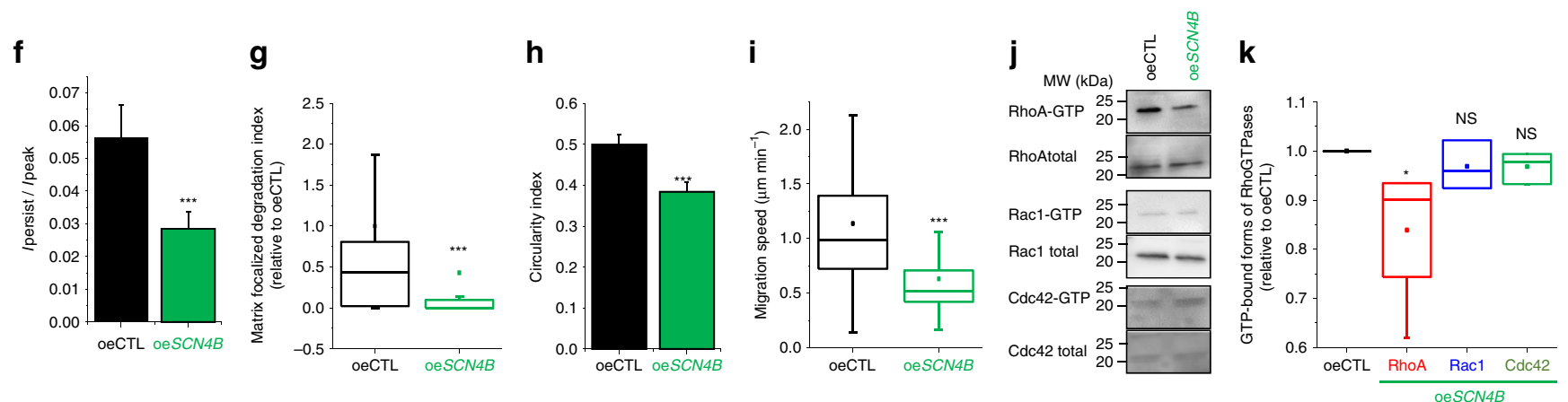

Figure 8 | SCN4B/ $\mathbf{\beta 4}$ protein overexpression inhibits cancer cell invasiveness. (a) CTL, shSCN4B and oeSCN4B cancer cell invasiveness, in the absence $(-)$ or presence of TTX $(30 \mu \mathrm{M})$, expressed relative to oeCTL cells in the absence of TTX $(n=6)$. Results are expressed as mean values \pm s.e.m. $\star \star \star$, different from CTL at $P<0.001,{ }^{\star \star}$ at $P<0.01$. \#\#, different from shSCN4B at $P<0.001$ (ANOVA). NS, no statistical difference. (b) Cancer cell invasiveness $(n=6)$ from oeCTL and oeSCN4B cells, in the absence $(-)$ or presence of TTX $(30 \mu \mathrm{M})$, expressed relative to oeCTL cells in the absence of

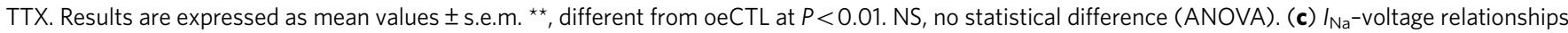
in oeCTL (black squares, $n=15$ ) and oeSCN4B (green triangles, $n=43$ ) cells. There was a significant difference at $P<0.05$ between the two conditions in the voltage range between -45 and $+45 \mathrm{mV}$. (d) Activation (filled circles)- and availability (filled squares)-voltage relationships obtained in the same oeCTL (black symbols) and oeSCN4B (green symbols) cells as in c. (e) Mean values \pm s.e.m. of $I_{\mathrm{Na}}$ persistent currents obtained for a membrane depolarization from -100 to $-30 \mathrm{mV}$ from 15 oeCTL and 43 oeSCN4B cells. ${ }^{\star} P<0.05$ from oeCTL (Student's $t$-test). (f) Mean values \pm s.e.m. of $I_{\text {Na }}$ persistent $/ I_{\mathrm{Na}}$ peak current ratios in same conditions as in $\mathbf{e} .{ }^{\star \star \star} P=0.001$ (Student's $t$-test). (g) oeCTL or oeSCN4B cells were cultured on a Matrigel-composed matrix containing DQ-Gelatin, and a 'Matrix-Focalized-degradation index' was calculated ( $n=77$ and 69 cells for oeCTL and oeSCN4B, respectively). ${ }^{\star \star \star}$, statistically different from oeCTL at $P<0.001(\mathrm{MW})$. (h) Cell circularity index was calculated from oeCTL and oeSCN4B cells ( $n=73$ cells per condition). Results are expressed as mean values \pm s.e.m. ${ }^{\star \star \star}$, statistically different from oeCTL at $P<0.001$ (Student's $t$-test). (i) Speed of migration ( $\mu \mathrm{m} \mathrm{min}^{-1}$ ) of oeCTL and oeSCN4B cells analysed from time-lapse experiments ( $n=47$ per condition). ${ }^{\star \star \star}$, statistically different from oeCTL at $P<0.001$ (MW). (j) Western blots showing total and active GTP-bound forms of RhoA, Rac1, Cdc42, pulled down by GST- in oeCTL and oeSCN4B cells. (k) Quantification of GTP-bound RhoGTPases in oeSCN4B cells, normalized to its total protein level, and expressed relatively to that of oeCTL cells ( $n=4$ ). ${ }^{\star}$, statistically different from the oeCTL at $P<0.05$. NS, no statistical difference $(\mathrm{MW})$. (g,i,k) Box plots indicate the first quartile, the median and the third quartile; whiskers indicate minimum and maximum values; squares show the means. Error bars encompass $95 \%$ of data samples.

We then studied the involvement of the $S C N 4 B$ gene and its expression product, the $S C N 4 B / \beta 4$ protein, in tumour progression. For this we used oeSCN4B and shSCN4B cells as models of cancer cells, coming from the same lineage and solely differing by the presence of high levels of $S C N 4 B / \beta 4$ protein (similar to non-cancerous mammary cells, oeSCN $4 B$ cells) or the complete absence of $S C N 4 B / \beta 4$ protein (similar to high-grade cancers, shSCN4B cells). We developed two in vivo models in immunodepressed mice. In the first model, we assessed the importance of $S C N 4 B$ expression in human breast cancer cells for the colonization of organs. ShSCN4B or oeSCN4B cells, both having identical in vitro growth and viability properties and similarly expressing the luciferase gene (Supplementary Fig. 8c-e), were injected in the tail vein of NMRI nude mice. After 9 weeks, there was no statistical difference in animal body weights between the two experimental groups (Supplementary Fig. 8f). Mice were euthanized and the isolated organs (lungs, brain, liver, bones from spine/ribs and legs) were analysed ex vivo for bioluminescent imaging after luciferin injection (Fig. 10c). In the shSCN4B group, all mice showed lung metastases (7/7), while in the oeSCN4B group, only one mouse out of eight had lung colonization and there was no bioluminescent signal in other organs (Yate's $\chi^{2}$,
$P=0.0041)$. Altogether, there was a strong reduction in lung colonization by cancer cells overexpressing $S C N 4 B / \beta 4$ compared with non-expressors (Fig. 10d). In the other model of orthotopic xenograft of mammary cancer, in which shSCN4B or oeSCN4B cells were injected into the mammary fat pad of NOD SCID mice, the primary tumour growth was analysed as a function of time for 23 weeks. There was no statistical difference in the evolution of animal body weights between the two experimental groups (8 mice/group; Supplementary Fig. 10a). The growth of primary mammary tumours, measured with a calliper (Supplementary Fig. 10b) or by bioluminescent imaging (Fig. 10e,f), was reduced in mice implanted with oeSCN4B cells compared with those implanted with $\operatorname{sh} S C N 4 B$. At the end of the study, primary mammary tumours from the two groups were analysed and the non-expression of $S C N 4 B / \beta 4$ in the $\operatorname{sh} S C N 4 B$ group or expression in the oeSCN $4 B$ group was confirmed by immunohistochemistry (Fig. 10g). Finally, 5/8 mice implanted with shSCN4B cells had more metastatic foci (3/8 in lungs, 1 in spine and 1 in posterior legs) compared with those implanted with oeSCN4B cells (only 1/8 mouse showed lung metastases) (Yates $\chi^{2} P$-value $=0.039$; Supplementary Fig. $\left.10 \mathrm{c}-\mathrm{e}\right)$. The presence of human breast cancer cells in mouse lungs was confirmed by 

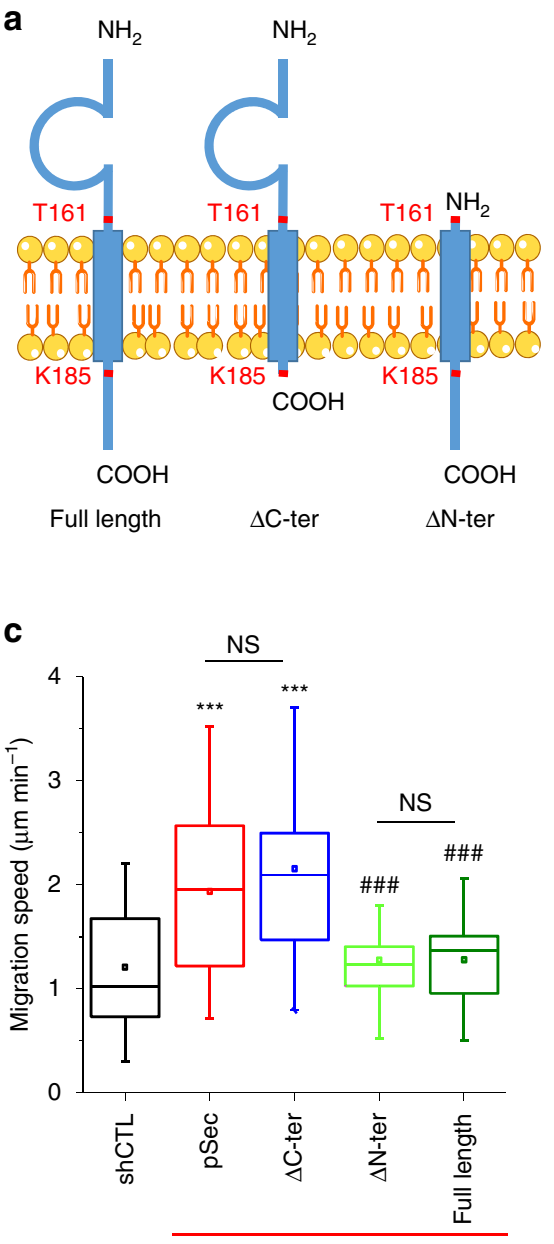

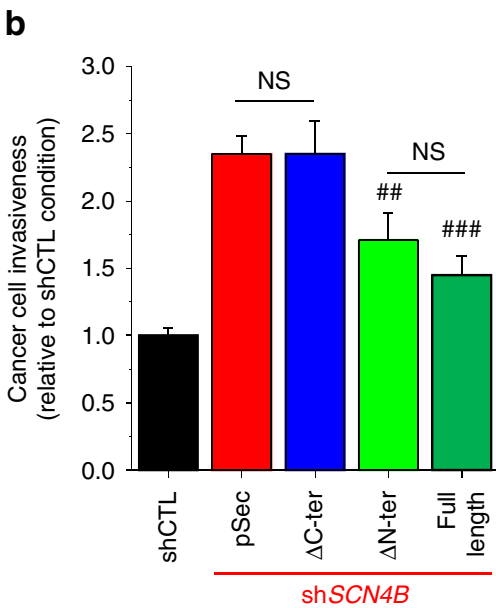

d

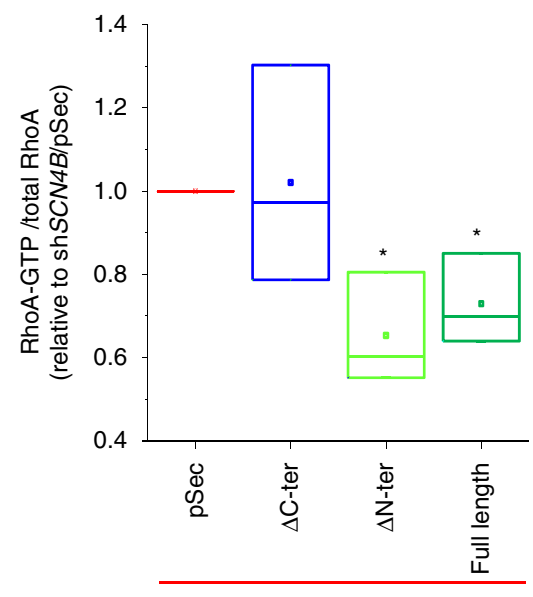

$\operatorname{shSCN4B}$

Figure 9 | SCN4B/ק4 protein inhibits cancer cell invasiveness through its intracellular C-terminus but not through its extracellular lg-like domain. (a) Cartoon showing the transmembrane structure of the $\beta 4$ protein, encoded by the SCN4B gene. The extracellular domain contains an Ig-like structure. After introduction of synonymous nucleotide substitutions in the SCN4B sequence, we have generated a sequence that is not recognized by the small hairpin RNA targeting SCN4B expression. This sequence has been inserted into a pSec expression vector in order to overexpress the full-length $\beta 4$ protein (called 'Full-length') in shSCN4B cells. Alternatively, we have also created truncated versions of the $\beta 4$ protein: one containing a deletion of its intracellular C-terminus, from residue $\mathrm{K} 185$, and called ' $\Delta \mathrm{C}$-ter', and one containing a deletion of its extracellular $\mathrm{N}$-terminus up to residue $\mathrm{T} 161$, and called ' $\Delta \mathrm{N}$-ter'. The nucleotide sequences were inserted into the pSec mammalian expression vector. (b) Cancer cell invasiveness was assessed using Matrigel-invasion chambers from shCTL and shSCN4B, transfected with an empty expression vector (pSec), or transfected with ' $\Delta \mathrm{N}$-ter', ' $\Delta \mathrm{C}$-ter' or 'Full-length' encoding

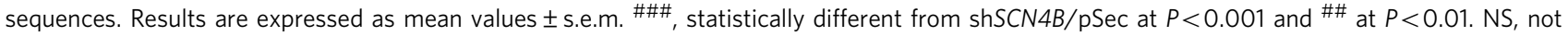
statistically different (ANOVA). (c) The speed of migration (in $\mu \mathrm{m} \mathrm{min}^{-1}$ ) was analysed from time-lapse experiments with shCTL and shSCN4B cells, transfected with an empty expression vector ( $\mathrm{pSec}$ ), or transfected with ' $\Delta \mathrm{N}$-ter', ' $\Delta \mathrm{C}$-ter' or 'Full-length' encoding sequences, and results shown were obtained from 30 cells in each condition. ***, statistically different from shCTL at $P<0.001$. \#\#\#, statistically different from shSCN4B/pSec at $P<0.001$. NS, not statistically different (Dunn's test). (d) Quantification of GTP-bound RhoA in shSCN4B cells, transfected with empty vector (pSec), with ' $\triangle N$-ter',

' $\Delta C$-ter' or 'Full-length' encoding sequences. The activity of GTP-bound (active) RhoAGTPase was normalized to its total protein level, and was expressed relatively to that of shSCN4B/pSec cells $(n=3)$. *, statistically different from shSCN4B/pSec at $P<0.05(\mathrm{MW})$. (c,d) Box plots indicate the first quartile, the median and the third quartile; whiskers indicate minimum and maximum values; squares show the means. Error bars encompass $95 \%$ of data samples.

human cytokeratin 7 immunoreactivity (Fig. 10h). All together, these results indicate that the overexpression of SCN4B in cancer cells reduces primary tumour growth and metastatic colonization.

\section{Discussion}

$S C N x B / \beta$ proteins were initially isolated from rat brain along with pore-forming $\mathrm{Na}_{\mathrm{V}}$ sodium channels ${ }^{43}$. They all exhibit an extracellular $\mathrm{N}$-terminus containing an immunoglobulin domain. With the exception of the soluble $\beta 1 \mathrm{~B}$ protein ${ }^{44}$, all $S C N x B / \beta$ subunits have a single $\alpha$-helical transmembrane domain and a short intracellular domain ${ }^{45}$. $S C N \times B / \beta$ proteins were demonstrated to interact, through covalent or non-covalent associations, with pore-forming Nav channels ${ }^{46-49}$, to regulate their trafficking to the plasma membrane, as well as their biophysical $^{50}$ and pharmacological ${ }^{51-53}$ properties. Because of these functions, $S C N x B / \beta$ proteins were initially characterized as being auxiliary subunits of pore-forming Nav in excitable cells. Besides these canonical roles, it has later been proposed that they might also have other specific cellular functions ${ }^{54}$. Indeed, the presence of an Ig motif in their extracellular domain, similar to that of CAMs such as integrins, cadherins and selectins, argued for a possible function in cell adhesion properties ${ }^{55,56}$. SCN1B/ $\beta 1$ and $S C N 2 B / \beta 2$ subunits were demonstrated to form both transhomophilic and trans-heterophilic cell-cell and cell-matrix adhesions in cells expressing $\mathrm{Nav}$, such as neurons in which 
a

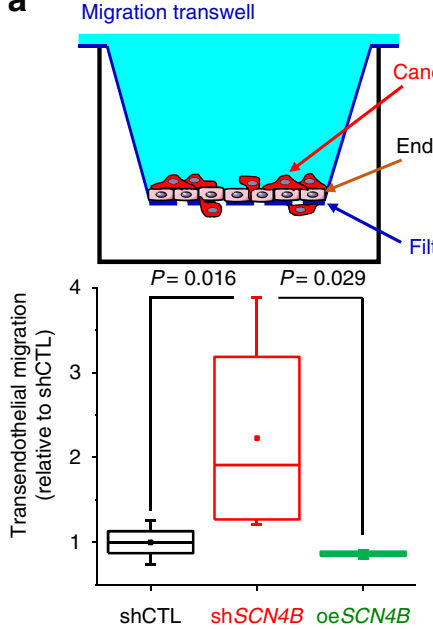

e

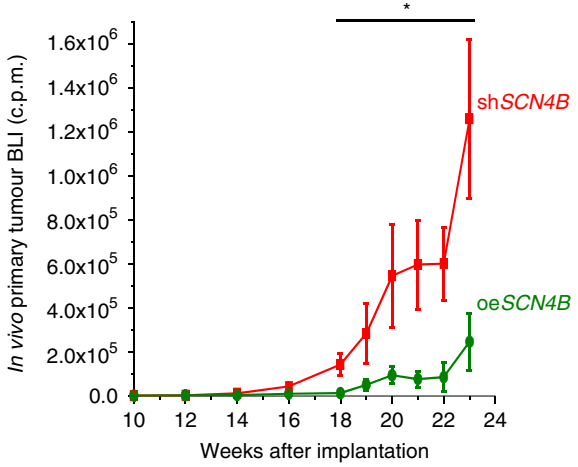

b

Invasion transwell

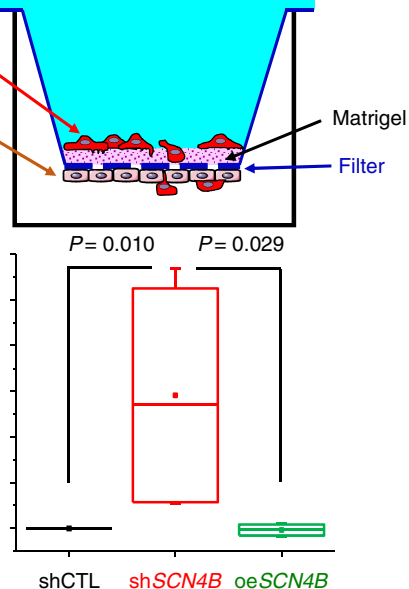

f $1 \begin{array}{llllll}1 & 2 & 3 & 4 & 5 & 6 \times 10^{2}\end{array}$

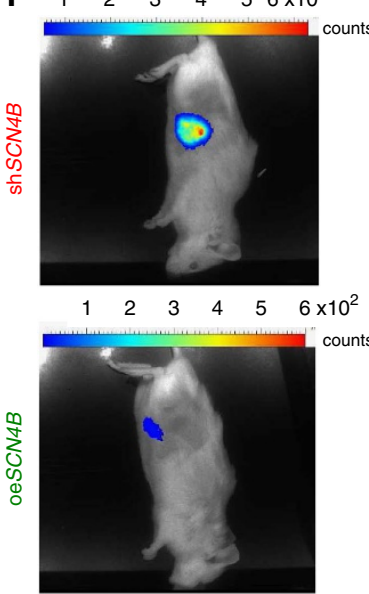

C
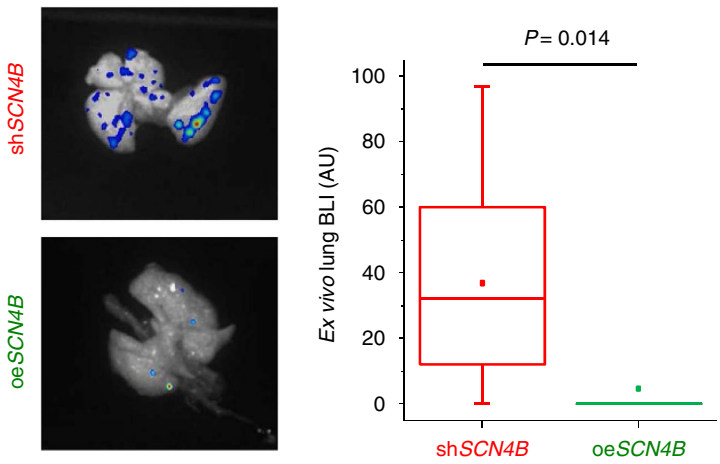

d g Primary mammary tumours
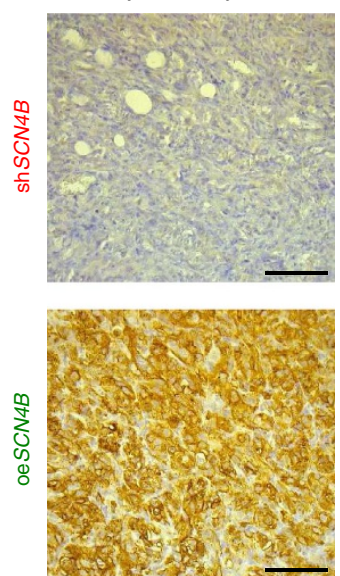

Figure 10 | SCN4B expression inversely correlates with primary tumour growth and metastatic development. (a) Top cartoon, transendothelial migration experiment. Bottom box plot, quantification of the number of ShCTL, shSCN4B or oeSCN4B cancer cells migrating through the endothelium (HUVEC monolayer) and the 8- $\mu \mathrm{m}$ pore-sized filter of the migration transwell, expressed as a relative number to shCTL (4 independent experiments). (b) Top cartoon, transendothelial invasion experiment. Bottom box plot, quantification of the number of shCTL, shSCN4B or oeSCN4B cancer cells migrating through the extracellular matrix (matrigel) coating the 8- $\mu \mathrm{m}$ pore-sized filter of the invasion transwell, then endothelium (HUVEC monolayer), expressed as a relative number to shCTL (three independent experiments). (c) Bioluminescent imaging (BLI) performed in NMRI nude mice tail vein-injected with MDA-MB-231-Luc cells that do not express (shSCN4B), or which overexpress, the SCN4B protein (oeSCN4B). Representative ex vivo lung BLI, after organ isolation, at completion of the study (ninth week after cell injection). (d) BLI quantification of excised lungs from mice injected with shSCN4B cells ( $n=7$ ) and mice injected with oeSCN4B cells $(n=8)(\mathrm{MW})$. (e) Mean \pm s.e.m. in vivo BLI value of tumours (expressed in c.p.m.) as a function of time recorded in the whole body of mice. ${ }^{*}$ denotes a statistical difference from the shSCN4B group at $P<0.05$ (Student's $t$-test). (f) Representative bioluminescent images of mammary tumours in shSCN4B and oeSCN4B experimental groups (23rd week after cell implantation). (g) Immunohistochemical analyses of primary mammary tumours obtained from same mice as in Fig. 8e,f implanted with shSCN4B cells (top image) or with oeSCN4B cells (bottom image). Slides were counterstained with haematoxylin (blue labelling), and incubated with anti-mouse SCN4B/ $\beta 4$ antibodies and immunohistochemistry was performed using the streptavidin-biotin-peroxidase method with diaminobenzidine as the chromogen (brown labelling). Scale bars, $100 \mu \mathrm{m}$. (h) Immunohistochemical analyses of lungs obtained from the same mice as in Fig. 6e,f, implanted with human shSCN4B cells (top image) and oeSCN4B cancer cells (bottom image). Slides were counterstained with haematoxylin (blue labelling), and human breast cancer cells were identified using anti-human cytokeratin 7

immunohistochemical (brown) labelling. Scale bars, $100 \mu \mathrm{m}$. (a,b,d) Box plots indicate the first quartile, the median and the third quartile; whiskers indicate minimum and maximum values; squares show the means. Error bars encompass $95 \%$ of data samples.

they were proven to be critical for neurites outgrowth, axonal fasciculation and interactions with glial cells ${ }^{14}$.

The expression of $S C N x B / \beta$ proteins and their physiological role in non-excitable cells have not been characterized. Their participation in oncogenic processes was not studied as much as that of pore-forming Nav proteins ${ }^{17}$. The most studied isoform in cancer is $S C N 1 B / \beta 1$, and results published so far could appear contradictory. An initial in vitro study indicated that the expression of $S C N 1 B / \beta 1$ was higher in poorly invasive than in highly invasive breast cancer cells. In weakly invasive MCF-7 cells, the downregulation of $S C N 1 B / \beta 1$ reduced cell adhesion, and increased cell migration. Correlatively, its overexpression in MDA-MB-231 cells, increased cell process length and adhesion, reduced lateral motility and cell proliferation ${ }^{33}$. These results suggested that $S C N 1 B / \beta 1$ expression could prevent cancer cell invasion. In contrast, a recent study demonstrated that $S C N 1 B / \beta 1$ was overexpressed in breast cancer biopsies, compared with non-cancer breast samples. Furthermore, the overexpression of $S C N 1 B / \beta 1$ in breast cancer cells potentiated their invasiveness in vitro, and increased primary tumour growth and metastatic 
development in vivo ${ }^{27}$. The proinvasive role of $S C N 1 B / \beta 1$ was proposed to depend on both Nav-dependent and Nav-independent mechanisms, relying on the extracellular Ig domain of the protein ${ }^{27}$. In this study, we found that $S C N 1 B$ gene is downregulated in breast cancer compared with normal breast tissues. Nevertheless, we identified $S C N 1 B$ as being the $S C N x B$ gene the most highly expressed in cancer cells. Interestingly, the downregulation of $S C N 1 B / \beta 1$ reduces in vitro invasiveness of MDA-MB-231, which is in line with results obtained by Nelson et al. $^{27}$ showing this isoform displays pro-invasive roles in vitro. Concerning the $S C N 4 B / \beta 4$ protein, there was no information regarding its potential involvement in the oncogenic process. Only one study identified that $S C N 4 B$ expression was decreased in cervical cancer biopsies compared with non-cancer samples 57 .

Aggressive cancer cells present an important plasticity enabling them to use different invasion modes, conferring an ability to adapt to their microenvironment, matrix composition, meshwork, eventually promoting tumour growth and metastases development. While RhoGTPases are involved in invasive phenotypes, the upstream mechanism regulating their respective activation is not known. Here, we identified the SCN4B gene as an important modulator of RhoA activity and invasiveness in cancer cells. The $S C N 4 B / \beta 4$ protein was known to be an auxiliary subunit of $\mathrm{Na}_{\mathrm{V}}$ in excitable cells. The present study shows for the first time that this protein is expressed in non-cancer epithelial cells, which do not express $\mathrm{Na}_{\mathrm{V}}$, suggesting a physiological non-auxiliary function. Furthermore, the expression of $S C N 4 B / \beta 4$ is reduced in cancer tissues, and more specifically when tumours gain invasive properties (transition from grade I to grade II). $S C N 4 B / \beta 4$ is almost absent in high-grade tumours and metastases. At the cellular level, the loss of $S C N 4 B / \beta 4$ in cancer cells further stimulates their invasiveness by favouring amoeboid migration, supported by the overactivation of the RhoA pathway, yet keeping the ECM-degradative activity intact. Conversely, the overexpression of $S C N 4 B / \beta 4$ reduces cancer cell invasiveness, tumour growth and metastatic progression, supporting our proposal that the $S C N 4 B$ gene is a metastasis-suppressor gene.

This study also demonstrates that the $S C N 4 B / \beta 4$ protein acts both as $\mathrm{Na}_{V}$ pore-subunit regulator and as RhoGTPases regulator in cancer cells. Indeed, the suppression of $S C N 4 B$ gene expression in cancer cells reduced the peak sodium current due to $\mathrm{Na}_{\mathrm{V}} 1.5$ activity. This could be attributed to a reduction of $S C N 5 A$ expression, and to a consequent reduction of channel density at the plasma membrane. However, we found that channels expressed at the plasma membrane of cancer cells show a higher activity through an increased persistent window current. The loss of interaction between $\mathrm{Na}_{\mathrm{V}} 1.5$ and $S C N 4 B / \beta 4$ protein might therefore be responsible for a gain-of-function of $\mathrm{Na}_{V} 1.5$. This is similar to what was observed in the case of the cardiac long QT syndrome LQT10, in which a missense mutation in the SCN4B gene, resulting in the $\mathrm{L} 1759 \mathrm{~F}$ amino acid substitution in the $\beta 4$ protein, induces a gain-of-function of $\mathrm{Na}_{\mathrm{V}} 1.5$ with an increased persistent sodium current ${ }^{29}$. Because of this regulation of $\mathrm{Na}_{V} 1.5$, the loss of $S C N 4 B$ expression in cancer cells left $\mathrm{Na}_{\mathrm{V}}$-dependent mesenchymal invasiveness unaffected, through the maintenance of a persistent sodium current that regulates ECM proteolysis, but also increased $\mathrm{Na}_{\mathrm{V}}$-independent amoeboid-related cell migration, through the dynamic regulation of RhoGTPases. This latter property is under the control of the intracellular C-terminus and is independent of the extracellular CAM domain. These results contrast with those obtained with the pro-invasive $S C N 1 B / \beta 1$ for which the extracellular Ig domain is crucial for its CAM function in breast cancer cells ${ }^{27}$. Our results further indicate that the intracellular C-terminus of SCN4B/ 34 might play a critical role in maintaining epithelial function and integrity.
In conclusion, this study shows that the loss of SCN4B gene expression in cancer cells promotes the acquisition of an amoeboid-mesenchymal hybrid phenotype, while its overexpression reduces both mesenchymal and amoeboid invasive capacities. The expression level of $S C N 4 B$ could therefore represent an important prognosis marker in cancers from epithelial origin.

\section{Methods}

Prognostic analyses of gene expression in breast cancers. Analyses were performed using the software Breast Cancer Gene-Expression Miner v3.0 (bc-GenExMiner v3.0; http://bcgenex.centregauducheau.fr) developed by the Integrated Center of Oncology René Gauducheau (Nantes-Saint Herblain, France), based on DNA microarrays results collected from published cohorts ${ }^{58}$. Briefly, several statistical tests were conducted on each cohort and on all cohorts pooled together with data from all studies previously converted to a common scale with a suitable normalization. The prognostic impact of each gene was evaluated by means of the univariate Cox proportional hazards model. Results were displayed by cohorts and pools and are illustrated in a forest plot. Kaplan-Meier curves were then obtained on the pool with the gene values dichotomized according to gene expression median (calculated from the pool). Cox results corresponding to dichotomized values were displayed on the graph.

In silico RNA expression analyses. Expression of $S C N x B$ genes in cancer tissues was studied using the web-based 'The Cancer Genome Atlas' (http:// cancergenome.nih.gov) from the US National Cancer Institute and the National Human Genome Research Institute that integrates RNE sequences databases. Data are expressed as RPKM (Reads Per Kilobase per Million).

Immunohistochemistry. The degree of $S C N 4 B / \beta 4$ protein expression in normal and dysplastic mammary tissues, as well as in mammary ductal and lobular carcinomas, was analysed by standard immunohistochemistry procedures. Tissue microarrays (TMA) from formalin-fixed, paraffin-embedded mammary tissues were purchased from US Biomax Inc. (ref. BR1003, BC081120, BR10010a; Rockville, USA), comprising normal, hyperplastic and dysplastic mammary samples, lobular and ductal mammary carcinomas (separated in well (grade I), moderately (grade II) and poorly (grade III) differentiated carcinomas) and LNM samples. Similar analyses were also performed in a lung TMA (LC951; US Biomax Inc) containing normal lung, cancer lung (grades IA to IIIB) tissues and metastases (in lymph nodes, bones and intestine). TMA were analysed in blind conditions by C.M.-C. (anatomopathologist) and P.P. (immunologist, Clinical University Hospital Virgen de la Arrixaca, Murcia, Spain). Normal breast and cancer biopsies from the University-Hospital of Tours were coming from the tumour collection declared to the French Ministry of Research (No. DC2008-308) and were prepared by R.G. and analysed by G.F. (clinical anatomothologist at the University-Hospital of Tours, France).

Briefly, after deparaffinization and rehydration, sections were treated with a high-pH (Tris buffer/EDTA, pH 9.0) target retrieval procedure (Dako PT-link; Dako, USA). Endogenous peroxidase was then blocked by a commercial solution (Dako REAL), and incubated overnight with a 1/100 dilution of the primary polyclonal rabbit antibody anti-SCN4B/ 34 protein (HPA017293; Sigma-Aldrich, France) at $4{ }^{\circ} \mathrm{C}$. The antibody used recognizes the following extracellular peptide sequence of the $\beta 4$ protein: LLPCTFSSCFGFEDLHFRWTYNSSDAFKILIEGTVK NEKSDPKVTLKDDDRITLVGSTKEKMNNISIVLRDLEFSDTGKYTCHVKNPK ENNLQHHATIFLQVV. Sections were then incubated with a commercial anti-rabbit-labelled polymer (Dako EnVision FLEX; Dako) for $30 \mathrm{~min}$ at RT. Immunoreaction was finally revealed with $3-3^{\prime}$ diaminobenzidine solution (Dako) for $5 \mathrm{~min}$. Positive reaction was identified by a cytoplasmic dark-brown precipitate. To determine the degree of protein expression in tissues, a qualitative scale was used, for negative $(-)$, weak $(+)$ and strong $(++)$ cytoplasmic expression. A unique score was given per core. The number of samples is representative of the number of cores, which is equivalent to the number of patients.

Lung and primary tumours from in vivo mouse experiments were fixed in formalin, included in paraffin, and cut in $5 \mu \mathrm{m}$ tissue sections. Slides were deparaffinized, rehydrated and heated in citrate buffer $\mathrm{pH} 6$ for antigenic retrieval. The primary antibodies included monoclonal anti-human cytokeratin 7 (clone OV-TL 12/30; Dakocytomation, Glostrup, Denmark, dilution 1/100, $1 \mathrm{~h}$ ), used on lung sections, and polyclonal anti-mouse $S C N 4 B / \beta 4$ (dilution $1 / 100,1 \mathrm{~h}$ ), used on primary tumour sections. Immunohistochemistry was performed using the streptavidin-biotin-peroxidase method with diaminobenzidine as the chromogen (Kit LSAB, Dakocytomation). Slides were finally counterstained with haematoxylin. Negative controls were obtained after omission of the primary antibody or incubation with an irrelevant antibody.

Reagents and antibodies. TTX was purchased from Latoxan (France), and A803467 from R\&D systems (France). Fluorescent probes and conjugated 
antibodies were purchased from Fisher Scientific (France). Drugs and chemicals were purchased from Sigma-Aldrich.

Cell culture and cell lines. All cell lines were from the American Type Culture Collection (LGC Promochem, France) and were grown at $37^{\circ} \mathrm{C}$ in a humidified $5 \%$ $\mathrm{CO}_{2}$ incubator. The immortalized normal mammary epithelial cells MCF-10A were cultured in Dulbecco's modified Eagle's medium (DMEM)/Ham's F-12, 1:1 mix containing $5 \%$ horse serum (Invitrogen, France), $10 \mu \mathrm{g} \mathrm{ml}^{-1}$ insulin, $20 \mathrm{ng} \mathrm{ml}^{-1}$ epidermal growth factor, $0.5 \mathrm{~g} \mathrm{ml}^{-1}$ hydrocortisone and $100 \mathrm{ng} \mathrm{ml}^{-1}$ cholera toxin. MCF-7, MDA-MB-468 and MDA-MB-435s breast cancer cells were cultured in DMEM supplemented with 5\% fetal calf serum (FCS). PC3 prostate, H460 and A549 non-small-cell lung cancer cells were cultured in DMEM supplemented with $10 \%$ FCS. MDA-MB-231-Luc human breast cancer cells, stably expressing the luciferase gene ${ }^{22}$, were cultured in DMEM supplemented with $5 \%$ FCS. We constructed a lentiviral vector encoding a short hairpin RNA (shRNA) specifically targeting human $S C N 5 A$ transcripts ${ }^{35}$. The sequence encoding shSCN5A, inhibiting the expression of $\mathrm{Na}_{\mathrm{V}} 1.5$ protein, was obtained by DNA polymerase fill-in of two partially complementary primers: 5'-GGATCCCCAAGGCACAAGTGCGTGCG CAATTCAAGAGA- ${ }^{\prime}$ and $5^{\prime}$-AAGCTTAAAAAAAGGCACAAGTGCGTGCG CAATCTCTTGAA- $3^{\prime}$

Similarly, we constructed a lentiviral vector encoding a short hairpin RNA (shRNA) specifically targeting human $S C N 4 B$ transcripts, inhibiting the expression of $\beta 4$ protein. The sequence encoding the shSCN4B was obtained by DNA polymerase fill-in of two partially complementary primers; this method also allowed the introduction of two restriction enzyme sites to facilitate manipulations. Forward primer: $\operatorname{sh} \beta 4$-BamHI $5^{\prime}$-GGATCCCCCAGCAGTGACGCATTCAAGA TTCTTCAAGAGA-3' ${ }^{\prime}$ and reverse primer: sh $\beta 4$-HindIII $5^{\prime}$-AAGCTTAAAAACA GCAGTGACGCATTCAAGATTCTCTCTTGAA- $3^{\prime}$. We also constructed a lentiviral vector expressing a null-target shRNA (pLenti-shCTL), using the following primers: $5^{\prime}$-GGATCCCCGCCGACCAATTCACGGCCGTTCAAGAG ACG- $3^{\prime}$ and $5^{\prime}$-AAGCTTAAAAAGCCGACCAATTCACGGCCGTCTCTTGA ACG-3' ${ }^{\prime}$. We constructed an expression plasmid containing the human $S C N 4 B$ coding sequence to overexpress $\beta 4$. This sequence was synthetized by Proteogenix (France) and inserted in pcDNA3.1, using the following sequences: $5^{\prime}$-GGATCC GCCGCCACC- $3^{\prime}$ and $5^{\prime}$-GCGGCCGCCTCGAG- ${ }^{\prime}$. We designed the mutated sequences coding for the 'Full-length $S C N 4 B / \beta 4^{\prime}$ ' and truncated proteins, which were then synthetized by Proteogenix (France) and all sequences obtained were inserted into pSecTag2 hygro B vector (V910-20; Invitrogen) with the In-fusion HD cloning Plus kit (Clonetech). We constructed a plasmid containing the sequence coding for the N-terminally truncated (from residue 1 to residue T161, ' $\Delta \mathrm{N}$-ter') protein containing the transmembrane and C-terminal intracellular domain of the $S C N 4 B / \beta 4$ protein. The sequence was obtained by PCR elongation using two specific primers: forward primer $5^{\prime}$-GCGCCGTACGAAGCTGACCT GGAGTTCAGCGAC- $3^{\prime}$ and reverse primer $5^{\prime}$ - ACACTGGAGTGGATCTCAC ACTTTTGAAGGTGGTT- $3^{\prime}$. Similarly, an $S C N 4 B / \beta 4$ protein truncated in the C-terminus, starting with residue K185 and identified as being ' $\Delta \mathrm{C}$-ter' was designed. Importantly, for ' $\Delta \mathrm{C}$-ter' and 'full-length' the nucleotide sequence was mutated by substitution to avoid targeting by the shRNA targeting native $S C N 4 B$ gene. The protein sequence remained unaffected. The sequence targeted by the shRNA was $5^{\prime}$-CAGCAGTGACGCATTCAAATTC- $3^{\prime}$, while the substituted untargeted sequence was $5^{\prime}$-TAGTAGCGATGCCTTTAAATAC- ${ }^{\prime}$. All variants exhibited an His-Tag and their expression and subcellular localization, after transfection of shSCN $4 B$ cells, were assessed by epifluorescence imaging using a primary rabbit anti-HisTag antibody (T2767; Invitrogen), and a secondary goat anti-rabbit Texas Red antibody (Thermofisher, France).

Mycoplasma contamination tests were performed every week (Lonza, MycoAlert Mycoplasma Detection Kit).

Reverse transcription of RNA and real-time PCR. Total RNA extraction was performed using the RNAgents Total RNA Isolation System (Promega, France). RNA yield and purity were determined by spectrophotometry and only samples with an A260/A280 ratio above 1.6 were kept for further experiments. Total RNA were reverse-transcribed with the RT kits Ready-to-go You-prime First-Strand Beads (Amersham Biosciences, UK). Random hexamers pd(N) ${ }_{6} 5^{\prime}$-phosphate $(0.2 \mu \mathrm{g}$; Amersham Biosciences) were added and the reaction mixture was incubated at $37^{\circ} \mathrm{C}$ for $60 \mathrm{~min}$. Real-time PCR experiments were performed as previously described ${ }^{24}$. Primers sequences are given in Supplementary Table 1.

siRNA transfection and efficacy assessment. MDA-MB-231-Luc human breast cancer cells were transfected with $20 \mathrm{nM}$ siRNA targeting the expression of $S C N 1 B$ (siSCN1B, sc-97849), SCN2B (siSCN2B, sc-96252), SCN4B (siSCN4B, sc-62982) or scrambled siRNA (siCTL, siRNA-A sc-37007), which were produced by Santa Cruz Biotechnology and were purchased from Tebu-Bio (France). Transfection was performed with Lipofectamine RNAi max (Invitrogen) according to the manufacturer's instructions, and used $24 \mathrm{~h}$ after transfection. The efficiency of siRNA transfection was verified by qPCR using an iCycler system (BioRad, USA) and by western blotting.

Western blotting experiments. Cells were washed with phosphate-buffered saline (PBS) and lysed in the presence of a lysis buffer ( $50 \mathrm{mM}$ Tris, pH 7, $100 \mathrm{mM} \mathrm{NaCl}$,
$5 \mathrm{mM} \mathrm{MgCl} 2,10 \%$ glycerol, $1 \mathrm{mM}$ EDTA), containing $1 \%$ Triton-X-100 and protease inhibitors (Sigma-Aldrich). Cell lysates were cleared by centrifugation at $16,000 \mathrm{~g}$ for $10 \mathrm{~min}$. Western blotting experiments were performed according to standard protocols. Total protein concentrations were determined using the Pierce BCA Protein Assay Kit Thermoscientific (Fisher Scientific, France). Protein sample buffer was added and the samples were boiled at $100^{\circ} \mathrm{C}$ for $3 \mathrm{~min}$. Total protein samples were electrophoretically separated by sodium dodecyl sulfate-polyacrylamide gel electrophoresis in $10 \%$ gels, and then transferred to polyvinylidene fluoride membranes (Millipore, USA). The $S C N \times B / \beta$ proteins were detected using anti-SCN1B/B1 (1/1,000, AV35028; Sigma-Aldrich), anti-SCN2B/B2 (1/200, HPA012585; Sigma-Aldrich) and anti-SCN4B/B4 (1/1,000, HPA01293, Sigma-Aldrich) rabbit polyclonal primary antibodies and horseradish peroxidaseconjugated goat anti-rabbit IgG secondary antibody at 1:2,000 (TebuBio, France) HSC70 protein was detected as a sample loading control using anti-HSC70 mouse primary antibody at 1:30,000 (TebuBio) and horseradish peroxidase -conjugated anti-mouse-IgG secondary antibodies at 1:2,000 (TebuBio). Proteins were revealed using electrochemiluminescence-plus kit (Pierce ECL Western Blotting Substrate; Fisher Scientific) and captured on Kodak Bio-Mark MS films (Sigma-Aldrich). Full scans of western blots are shown in Supplementary Fig. 11.

RhoGTPases pull-down assays. Pull-down assays were performed according to the manufacturer's protocol (Cat\#BK030, RhoA/Rac1/Cdc42 Activation Assay Combo Biochem Kit; Cytoskeleton, Inc.). Briefly, cells were washed on ice with ice-cold PBS, then lysed and scraped with ice-cold cell lysis buffer containing protease inhibitors (Sigma-Aldrich). Cell lysates were clarified by centrifugation at $10,000 \mathrm{~g},+4{ }^{\circ} \mathrm{C}, 1 \mathrm{~min}$, and the supernatant was snap-frozen in liquid nitrogen. Ten microlitres of clarified cell lysate were used to perform the protein assay (Cat\#23225, BCA protein assay; Thermofisher). Total proteins $(300 \mu \mathrm{g})$ were incubated with $10 \mu \mathrm{g}$ of PAK-PDB beads or $30 \mu \mathrm{g}$ Rhotekin-RBD beads for $1 \mathrm{~h}$ on a rotator at $+4^{\circ} \mathrm{C}$. Samples and beads were washed with $500 \mu$ l washing buffer, resuspended in Laemmli buffer and boiled for 2 min prior to performing western blotting experiments. Antibodies for RhoA, Racl and Cdc42 were provided with the kit and used according to the manufacturer's protocol.

Cellular electrophysiology. Patch pipettes were pulled from borosilicate glass to a resistance of 3-5 M $\Omega$. Currents were recorded, in whole-cell configuration, under voltage-clamp mode of the patch-clamp technique, at room temperature, using an Axopatch 200B patch clamp amplifier (Axon Instrument, USA). Analogue signals were filtered at $5 \mathrm{kHz}$, and sampled at $10 \mathrm{kHz}$ using a 1,440A Digidata converter. Cell capacitance and series resistance were electronically compensated by about $60 \%$. The $\mathrm{P} / 2$ sub-pulse correction of cell leakage and capacitance was used to study $\mathrm{Na}^{+}$current $\left(I_{\mathrm{Na}}\right)$. Sodium currents were recorded by depolarizing the cells from a holding potential of $-100 \mathrm{mV}$ to a maximal test pulse of $-30 \mathrm{mV}$ for $30 \mathrm{~ms}$ every $500 \mathrm{~ms}$. The protocol used to build sodium current-voltage $\left(I_{\mathrm{Na}}-V\right)$ relationships was as follows: from a holding potential of $-100 \mathrm{mV}$, the membrane was stepped to potentials from -80 to $+60 \mathrm{mV}$, with $5-\mathrm{mV}$ increments, for $50 \mathrm{~ms}$ at a frequency of $2 \mathrm{~Hz}$. Availability-voltage relationships were obtained by applying $50 \mathrm{~ms}$ prepulses using the $I_{\mathrm{Na}}-V$ curve procedure followed by a depolarizing pulse to $-5 \mathrm{mV}$ for $50 \mathrm{~ms}$. In this case, currents were normalized to the amplitude of the test current without a prepulse. Conductance through $\mathrm{Na}^{+}$channels $\left(g_{\mathrm{Na}}\right)$ was calculated as already described ${ }^{21}$. Current amplitudes were normalized to cell capacitance and expressed as current density $(\mathrm{pA} / \mathrm{pF})$. The Physiological Saline Solution had the following composition (in $\mathrm{mM}$ ): $\mathrm{NaCl} 140, \mathrm{KCl} 4, \mathrm{MgCl}_{2} 1, \mathrm{CaCl}_{2}$ 2, D-glucose 11.1 and HEPES 10, adjusted to $\mathrm{pH} 7.4$ with $\mathrm{NaOH}(1 \mathrm{M})$. The intrapipette solution had the following composition (in $\mathrm{mM}$ ): $\mathrm{KCl} \mathrm{130,} \mathrm{NaCl} 15$, $\mathrm{CaCl}_{2}$ 0.37, $\mathrm{MgCl}_{2} 1, \mathrm{Mg}$-ATP 1, EGTA 1, HEPES 10, adjusted to $\mathrm{pH} 7.2$ with $\mathrm{KOH}(1 \mathrm{M})$.

Measurement of intracellular pH. Cells were incubated for $30 \mathrm{~min}$ at $37^{\circ} \mathrm{C}$ in Hank's medium containing $2 \mu \mathrm{M}$ BCECF-AM (2',7'-bis-(2-carboxyethyl)-5(and-6)-carboxyfluorescein; excitation 503/440 nm; emission $530 \mathrm{~nm}$ ). Excess dye was removed by rinsing the cells twice with Physiological Saline Solution. $\mathrm{H}^{+}$efflux was measured as previously described ${ }^{25,59}$

Cell viability. Cells were seeded at $4 \times 10^{4}$ cells per well in a 24 -well plate and were grown for a total of 5 days. Culture media were changed every day. Viable cell numbers were assessed by the tetrazolium salt assay as previously described ${ }^{24}$ and normalized to the appropriate control condition (MDA-MB-231-Luc or shCTL).

In vitro invasion assays. Cell invasiveness was analysed as previously described ${ }^{25}$ using culture inserts with $8-\mu \mathrm{m}$ pore size filters covered with Matrigel (Becton Dickinson, France). Briefly, the upper compartment was seeded with $6 \times 10^{4}$ cells in DMEM supplemented with 5\% FCS. The lower compartment was filled with DMEM supplemented with 10\% FCS (or 15\% FCS for non-small-cell lung and prostate cancer cells), as a chemoattractant. After $24 \mathrm{~h}$ at $37^{\circ} \mathrm{C}$, remaining cells were removed from the upper side of the membrane. Cells that had invaded and migrated through the insert and were attached to the lower side were stained with 
DAPI and counted on the whole area of the insert membrane. In vitro invasion assays were performed in triplicate in each separate experiment.

3D invasion assays. Five thousand shCTL or shSCN4B MDA-MB-231-luc cells were suspended in DMEM containing Matrigel (Corning; ref 356230, $2.7 \mathrm{mg} \mathrm{ml}^{-1}$ final concentration), seeded in 96 -well microplates and placed at $37^{\circ} \mathrm{C}, 5 \% \mathrm{CO}_{2}$. One hundred microlitres of DMEM + 5\% FBS were added in each well 30 min after seeding. Time-lapse acquisitions ( 1 image per $30 \mathrm{~min}$ for a total duration of $48 \mathrm{~h}$ ) were performed in the presence or absence of the MMP inhibitor GM6001 $(10 \mu \mathrm{M}$ final concentration) to monitor $3 \mathrm{D}$ cancer cell invasiveness and started $4 \mathrm{~h}$ after cell seeding.

Epifluorescence imaging. For the assessment of ECM degradation, cells were cultured for $24 \mathrm{~h}$ on glass coverslips coated with a matrix composed of Matrigel $\left(4 \mathrm{mg} \mathrm{ml}^{-1}\right.$, final concentration) and containing or not DQ-gelatin $\left(25 \mu \mathrm{g} \mathrm{ml}^{-1}\right.$, Thermofisher) as a fluorogenic substrate of gelatinases. They were then washed in PBS, fixed with $3.7 \%$ ice-cold paraformaldehyde in PBS. Cells were permeabilized with a solution containing $50 \mathrm{mM} \mathrm{NH}_{4} \mathrm{Cl}, 1 \% \mathrm{BSA}$ and $0.02 \%$ saponin, then saturated in a solution containing $3 \% \mathrm{BSA}$ and $3 \%$ normal goat serum . F-actin was stained with phalloidin-AlexaFluor594. Epifluorescence microscopy was performed with a Nikon TI-S microscope and analysed using both NIS-BR software (Nikon, France) and ImageJ software 1.38I (http://rsbweb.nih.gov/ij). Pixels corresponding to the co-localization of F-actin condensation areas and focal spots of DQ-gelatin proteolysis (excitation wavelength: $495 \mathrm{~nm}$, emission wavelength: $515 \mathrm{~nm}$ ) were quantified per cell, giving a Matrix-focalized-degradation index.

Phospho (Y421)-cortactin was detected using the primary rabbit anti-pY421 cortactin antibody (Millipore) and the fluorescent-conjugated secondary anti-rabbit TexasRed antibody (Thermofisher). Pixels corresponding to the co-localization of phospho-cortactin and focal spots of DQ-gelatin proteolysis were quantified per cell using ImageJ software 1.38I.

For the assessment of cell morphology, cells were cultured for $24 \mathrm{~h}$ on glass coverslips and F-actin was stained with phalloidin-AlexaFluor594. A circularity index was calculated from pictures as being $4 \pi \cdot$ area/perimeter ${ }^{2}$. A value approaching 0 indicates an increasingly elongated shape while a value of 1.0 indicates a perfect circle.

Proximity ligation assays were performed according to the standard protocols ${ }^{26}$ using the Duolink-'In-cell Co-IP' kit (OLink Biosciences) ${ }^{60}$ using anti-SCN $4 B$ and Anti-RhoA primary antibodies.

Confocal imaging. 5,000 cells were seeded on Labtek coverslips (Thermofisher) and placed in the incubator at $37^{\circ} \mathrm{C}, 5 \% \mathrm{CO}_{2}$ for $24 \mathrm{~h}$. They were then washed twice in PBS, fixed with 3.7\% ice-cold paraformaldehyde in PBS. Cells were permeabilized with a solution containing $50 \mathrm{mM} \mathrm{NH}_{4} \mathrm{Cl}$, 1\% BSA and $0.02 \%$ saponin, then saturated in a solution containing 3\% BSA and 3\% normal goat serum. F-actin was stained with phalloidin-AlexaFluor488 (Thermofisher). Cells were observed on a confocal microscope, at $\times 600$ magnification (Olympus Fluoview FV500 Laser Scanning Confocal Biological Microscope) and image acquisition was performed using Fluoview 500 v.5 software (Olympus, Tokyo, Japan).

Scanning electron microscopy. Cells were fixed by incubation for $24 \mathrm{~h}$ in $4 \%$ paraformaldehyde, $1 \%$ glutaraldehyde in $0.1 \mathrm{M}$ phosphate buffer ( $\mathrm{pH}$ 7.2). They were then washed in PBS and post-fixed by incubation with $2 \%$ osmium tetroxide for $1 \mathrm{~h}$. Samples were then fully dehydrated in a graded series of ethanol solutions and dried in hexamethyldisilazane (HMDS; Sigma, USA). Finally, cells were coated with $40 \AA$ platinum, using a GATAN PECS 682 apparatus (Pleasanton, USA), before observation under a Zeiss Ultra plus FEG-SEM scanning electron microscope (Oberkochen, Germany). Cells were pseudocolored using PowerPoint software (Microsoft, USA).

Zebrafish invasion assays. Zebrafish (Danio rerio), from the Zebrafish International Resource Centre (ZIRC), were maintained in re-circulating tanks according to the standard procedures ${ }^{61}$. Adult fishes were maintained at $26^{\circ} \mathrm{C}$, with a light/dark cycle of $14 / 10 \mathrm{~h}$, and were fed twice daily, once with dry flake food (PRODAC) and once with live Artemia salina (MC 450, IVE AQUACULTURE). Zebrafish embryos were maintained in egg water at $28.5^{\circ} \mathrm{C}$, fed for 5 days with NOVO TOM and with live A. salina at 11 days of life. All experiments were performed in compliance with the Guidelines of the European Union Council for animal experimentation $(86 / 609 / \mathrm{EU})$ and were approved by the Bioethical Committee of the University Hospital Virgen de la Arrixaca (Spain). The colonization of zebrafish embryos was previously described ${ }^{35}$. Briefly, MDA-MB231 breast cancer cells transfected with siRNA targeting the expression of $S C N 4 B$ gene (SiSCN4B) or null-target siRNA (siCTL) were trypsinized $24 \mathrm{~h}$ after transfection, washed and stained with the vital cell tracker red fluorescent CM-Dil (Vibrant; Invitrogen). Fifty labelled cells were injected into the yolk sac of dechorionated zebrafish embryos using a manual injector (Narishige). Fish with fluorescently labelled cells appearing outside of the implantation area at $2 \mathrm{~h}$ postinjection were excluded from further analysis. All other fishes were incubated at $35^{\circ} \mathrm{C}$ for $48 \mathrm{~h}$ and analysed with a SteReo Lumar V12 stereomicroscope equipped with an AxioCam MR5 camera (Carl Zeiss). The evaluation criteria for embryos being colonized by human cancer cells was the presence of more than five cells outside of the yolk sac. A zebrafish (ZF) colonization index was calculated as being the proportion of embryos being colonized (by at least five human cancer cells) in the siSCN $4 B$ condition divided by the proportion of invaded embryos in the siCTL condition.

Transendothelial migration/invasion. Human umbilical vein endothelial cell (HUVEC; Promocell, Germany) were cultured in medium 199 (1X; Gibco) containing $20 \% \mathrm{FCS}, 100 \mu \mathrm{g} \mathrm{ml}^{-1}$ heparin and $50 \mathrm{\mu g} \mathrm{ml}^{-1}$ of endothelial cell growth supplement (Sigma-Aldrich) and were used up to the fifth passage. For transendothelial migration, 100,000 HUVEC were seeded in the upper side of $8-\mu \mathrm{m}$-pore sized transwell migration inserts (Corning, France) and grown for 6 days. Endothelial culture medium was carefully removed and replaced by DMEM $10 \%$ FCS in the lower chamber and DMEM 5\% FCS containing 60,000 MDA-MB-231 in the upper chamber. MDA-MB-231 cells were stained with $4 \mathrm{ng} \mathrm{Il}^{-1} \mathrm{CM}$-Dil (Thermo Fisher Scientific) prior seeding.

For transendothelial invasion, matrigel-coated transwell invasion inserts were inverted in order to plate the bottom surface with 100,000 HUVEC for $4 \mathrm{~h}$ at $37^{\circ} \mathrm{C}$, $5 \% \mathrm{CO}_{2}$. Invasion chambers were then inverted again, inserted into a 24 -well plates and HUVEC were cultured for 6 days in endothelial culture medium before plating MDA-MB-231 cells in the upper chamber. MDA-MB-231 cells were CM-Dil stained as described above. After $18 \mathrm{~h}$ of culture, transwells were washed in PBS and fixed in formaldehyde $4 \%$ for $20 \mathrm{~min}$.

Transendothelial electrical resistance measurements were recorded every day for 6 days until the transendothelial resistance was stable $(>10 \mathrm{k} \Omega)$ on the same transwells using an EVOM2 epithelial Voltohmmeter (World Precision Instruments, France).

In vivo tumour models. All animals were bred and housed at the In Vivo platform of the Cancéropôle Grand Ouest at Inserm U892 (Nantes, France) under the animal care license no. 44278. The project was approved by the French national ethical committee (APAFIS 00085.01).

Unanaesthetized six-week-old female NMRI Nude Mice (Charles River Laboratories) were placed into a plastic restraining device, and $2 \times 10^{6} \mathrm{MDA}-\mathrm{MB}$ 231-Luc cells (shSCN4B, 7 mice/oeSCN4B, 8 mice) suspended in $100 \mu$ PBS were injected into the lateral tail vein through a 25 -gauge needle as previously described $^{22}$. At necropsy, ex vivo BLI measurement for each collected organ was performed within $15 \mathrm{~min}$ of D-luciferin intraperitoneal injection $\left(150 \mathrm{mg} \mathrm{kg}^{-1}\right)$. Photons emitted by cancer cells were counted by bioluminescent imaging (ФimagerTM; BIOSPACE Lab) and expressed in counts per minute (c.p.m.).

Six-week-old female Rag2 - / - Il2rg - / - mice (NOD SCID; Charles River Laboratories) were injected into the sixth right inguinal mammary fat pad with $2 \times 10^{6}$ MDA-MB-231-Luc cells (shSCN4B or oeSCN4B, 8 mice per group) suspended in $100 \mu \mathrm{l}$ PBS while under isoflurane anaesthesia. Tumour growth was monitored by bioluminescence imaging ${ }^{22}$. Animal weight was measured every week or every other week, and the primary tumour volume $\left(\mathrm{mm}^{3}\right)$ was measured with a calliper and calculated as length $\times$ height $\times$ width (in $\mathrm{mm}$ ). Mice were euthanized 24 weeks following implantation of tumour cells and metastatic bioluminescence was measured ${ }^{22}$.

Statistical analyses. Statistical analyses on immunohistochemistry staining were performed using the Yate's $\chi^{2}$ test using the online interactive Chi-square test software Quantpsy (http://www.quantpsy.org/chisq/chisq.htm). Other data were displayed as mean \pm s.e.m. and $n=$ sample size, and were analysed using parametric statistical tests (Student's $t$-test or ANOVA) when they followed a normal distribution and equal variances. Alternatively, when samples did not follow a normal distribution, or when variances failed to be comparable, data were displayed as box plots indicating the first quartile, the median and the third quartile, and squares for comparison of means. In these cases, adequate non-parametric statistical tests were used (Mann-Whitney rank sum tests, Dunn's tests, ANOVA on ranks). Statistical analyses were performed using SigmaStat 3.0 software (Systat software Inc.) and statistical significance is indicated as ${ }^{\star} P<0.05 ;{ }^{*} P<0.01$ and ${ }^{* * *} P<0.001$. NS stands for not statistically different.

Data availability. Expression of $S C N x B$ genes in cancer tissues was studied using the web-based 'The Cancer Genome Atlas' (http://cancergenome.nih.gov). The authors declare that all other data supporting the findings of this study are available within the paper and its Supplementary Information files or available from the authors upon request.

\section{References}

1. Parkin, D. M., Bray, F., Ferlay, J. \& Pisani, P. Global cancer statistics, 2002. CA Cancer J. Clin. 55, 74-108 (2005).

2. Fidler, I. J. Understanding bone metastases: the key to the effective treatment of prostate cancer. Clin. Adv. Hematol. Oncol. 1, 278-279 (2003).

3. Friedl, P. \& Alexander, S. Cancer invasion and the microenvironment: plasticity and reciprocity. Cell 147, 992-1009 (2011).

4. Linder, S., Wiesner, C. \& Himmel, M. Degrading devices: invadosomes in proteolytic cell invasion. Annu. Rev. Cell Dev. Biol. 27, 185-211 (2011). 
5. Brisson, L., Reshkin, S. J., Gore, J. \& Roger, S. pH regulators in invadosomal functioning: proton delivery for matrix tasting. Eur. J. Cell Biol. 91, 847-860 (2012).

6. Wolf, K. \& Friedl, P. Extracellular matrix determinants of proteolytic and non-proteolytic cell migration. Trends Cell Biol. 21, 736-744 (2011).

7. Sanz-Moreno, V. et al. Rac activation and inactivation control plasticity of tumor cell movement. Cell 135, 510-523 (2008).

8. Sahai, E. \& Marshall, C. J. Differing modes of tumour cell invasion have distinct requirements for Rho/ROCK signalling and extracellular proteolysis. Nat. Cell Biol. 5, 711-719 (2003).

9. Wyckoff, J. B., Pinner, S. E., Gschmeissner, S., Condeelis, J. S. \& Sahai, E. ROCK- and myosin-dependent matrix deformation enables proteaseindependent tumor-cell invasion in vivo. Curr. Biol. 16, 1515-1523 (2006).

10. Friedl, P. \& Wolf, K. Tumour-cell invasion and migration: diversity and escape mechanisms. Nat. Rev. Cancer 3, 362-374 (2003).

11. Wolf, K. et al. Compensation mechanism in tumor cell migration: mesenchymal-amoeboid transition after blocking of pericellular proteolysis. J. Cell Biol. 160, 267-277 (2003).

12. Goldin, A. L. et al. Nomenclature of voltage-gated sodium channels. Neuron $\mathbf{2 8}$, 365-368 (2000).

13. Catterall, W. A. Voltage-gated sodium channels at 60: structure, function, and pathophysiology. J. Physiol. 590, 2577-2589 (2012).

14. O’Malley, H. A. \& Isom, L. L. Sodium channel beta subunits: emerging targets in channelopathies. Annu. Rev. Physiol. 77, 481-504 (2015).

15. Black, J. A. \& Waxman, S. G. Noncanonical roles of voltage-gated sodium channels. Neuron 80, 280-291 (2013).

16. Besson, P. et al. How do voltage-gated sodium channels enhance migration and invasiveness in cancer cells? Biochim. Biophys. Acta 1848, 2493-2501 (2015).

17. Roger, S., Gillet, L., Le Guennec, J. Y. \& Besson, P. Voltage-gated sodium channels and cancer: is excitability their primary role? Front. Pharmacol. 6, 152 (2015).

18. Brackenbury, W. J. Voltage-gated sodium channels and metastatic disease. Channels (Austin) 6, 352-361 (2012).

19. Yang, M. et al. Therapeutic potential for phenytoin: targeting $\mathrm{Na}_{\mathrm{v}} 1.5$ sodium channels to reduce migration and invasion in metastatic breast cancer. Breast Cancer Res. Treat. 134, 603-615 (2012).

20. Fraser, S. P. et al. Voltage-gated sodium channel expression and potentiation of human breast cancer metastasis. Clin. Cancer Res. 11, 5381-5389 (2005).

21. Roger, S., Besson, P. \& Le Guennec, J. Y. Involvement of a novel fast inward sodium current in the invasion capacity of a breast cancer cell line. Biochim. Biophys. Acta 1616, 107-111 (2003).

22. Driffort, V. et al. Ranolazine inhibits $\mathrm{Na}_{\mathrm{v}} 1.5$-mediated breast cancer cell invasiveness and lung colonization. Mol. Cancer 13, 264 (2014).

23. Nelson, M., Yang, M., Dowle, A. A., Thomas, J. R. \& Brackenbury, W. J. The sodium channel-blocking antiepileptic drug phenytoin inhibits breast tumour growth and metastasis. Mol. Cancer 14, 13 (2015).

24. Gillet, L. et al. Voltage-gated sodium channel activity promotes cysteine cathepsin-dependent invasiveness and colony growth of human cancer cells. J. Biol. Chem. 284, 8680-8691 (2009).

25. Brisson, L. et al. $\mathrm{Na}_{\mathrm{V}} 1.5$ enhances breast cancer cell invasiveness by increasing NHE1-dependent $\mathrm{H}^{+}$) efflux in caveolae. Oncogene 30, 2070-2076 (2011)

26. Brisson, L. et al. $\mathrm{Na}_{\mathrm{v}} 1.5 \mathrm{Na}^{+}$channels allosterically regulate the NHE-1 exchanger and promote the activity of breast cancer cell invadopodia. J. Cell Sci. 126, 4835-4842 (2013).

27. Nelson, M., Millican-Slater, R., Forrest, L. C. \& Brackenbury, W. J. The sodium channel betal subunit mediates outgrowth of neurite-like processes on breast cancer cells and promotes tumour growth and metastasis. Int. J. Cancer 135, 2338-2351 (2014).

28. Yu, F. H. et al. Sodium channel beta4, a new disulfide-linked auxiliary subunit with similarity to beta2. J. Neurosci. 23, 7577-7585 (2003).

29. Medeiros-Domingo, A. et al. SCN4B-encoded sodium channel beta4 subunit in congenital long-QT syndrome. Circulation 116, 134-142 (2007).

30. Tan, B. H. et al. Sudden infant death syndrome-associated mutations in the sodium channel beta subunits. Heart Rhythm 7, 771-778 (2010).

31. Okayama, H. et al. Identification of genes upregulated in ALK-positive and EGFR/KRAS/ALK-negative lung adenocarcinomas. Cancer Res. 72, 100-111 (2012).

32. Hou, J. et al. Gene expression-based classification of non-small cell lung carcinomas and survival prediction. PLoS ONE 5, e10312 (2010).

33. Chioni, A. M., Brackenbury, W. J., Calhoun, J. D., Isom, L. L. \& Djamgoz, M. B. A novel adhesion molecule in human breast cancer cells: voltage-gated $\mathrm{Na}^{+}$ channel betal subunit. Int. J. Biochem. Cell Biol. 41, 1216-1227 (2009).

34. Marques, I. J. et al. Metastatic behaviour of primary human tumours in a zebrafish xenotransplantation model. BMC Cancer 9, 128 (2009).

35. Jelassi, B. et al. P2X(7) receptor activation enhances SK3 channels- and cystein cathepsin-dependent cancer cells invasiveness. Oncogene 30, 2108-2122 (2011).
36. Roger, S., Guennec, J. Y. \& Besson, P. Particular sensitivity to calcium channel blockers of the fast inward voltage-dependent sodium current involved in the invasive properties of a metastastic breast cancer cell line. Br. J. Pharmacol. 141, 610-615 (2004)

37. Wannous, R. et al. Suppression of PPARbeta, and DHA treatment, inhibit NaV1.5 and NHE-1 pro-invasive activities. Pflugers Arch. 467, 1249-1259 (2015).

38. Jarvis, M. F. et al. A-803467, a potent and selective $\mathrm{Na}_{\mathrm{v}} 1.8$ sodium channel blocker, attenuates neuropathic and inflammatory pain in the rat. Proc. Natl. Acad. Sci. USA 104, 8520-8525 (2007).

39. Roger, S. et al. Voltage-gated sodium channels potentiate the invasive capacities of human non-small-cell lung cancer cell lines. Int. J. Biochem. Cell Biol. 39, 774-786 (2007).

40. Diss, J. K., Archer, S. N., Hirano, J., Fraser, S. P. \& Djamgoz, M. B. Expression profiles of voltage-gated $\mathrm{Na}^{+}$channel alpha-subunit genes in rat and human prostate cancer cell lines. Prostate 48, 165-178 (2001).

41. Saltel, F. et al. Invadosomes: intriguing structures with promise. Eur. J. Cell Biol. 90, 100-107 (2011)

42. Kovacs, M., Toth, J., Hetenyi, C., Malnasi-Csizmadia, A. \& Sellers, J. R. Mechanism of blebbistatin inhibition of myosin II. J. Biol. Chem. 279, 35557-35563 (2004).

43. Messner, D. J. \& Catterall, W. A. The sodium channel from rat brain. Separation and characterization of subunits. J. Biol. Chem. 260, 10597-10604 (1985).

44. Qin, N. et al. Molecular cloning and functional expression of the human sodium channel beta1B subunit, a novel splicing variant of the betal subunit. Eur. J. Biochem. 270, 4762-4770 (2003).

45. Brackenbury, W. J. \& Isom, L. L. Na channel beta subunits: overachievers of the ion channel family. Front. Pharmacol. 2, 53 (2011).

46. McCormick, K. A. et al. Molecular determinants of $\mathrm{Na}^{+}$channel function in the extracellular domain of the betal subunit. J. Biol. Chem. 273, 3954-3962 (1998).

47. Meadows, L., Malhotra, J. D., Stetzer, A., Isom, L. L. \& Ragsdale, D. S. The intracellular segment of the sodium channel betal subunit is required for its efficient association with the channel alpha subunit. J. Neurochem. 76, 1871-1878 (2001).

48. Chen, C. et al. Identification of the cysteine residue responsible for disulfide linkage of $\mathrm{Na}^{+}$channel alpha and beta2 subunits. J. Biol. Chem. 287, 39061-39069 (2012).

49. Gilchrist, J., Das, S., Van Petegem, F. \& Bosmans, F. Crystallographic insight into sodium-channel modulation by the beta4 subunit. Proc. Natl. Acad. Sci. USA 110, E5016-E5024 (2013)

50. Calhoun, J. D. \& Isom, L. L. The role of non-pore-forming beta subunits in physiology and pathophysiology of voltage-gated sodium channels. Handb. Exp. Pharmacol. 221, 51-89 (2014).

51. Lenkowski, P. W., Shah, B. S., Dinn, A. E., Lee, K. \& Patel, M. K. Lidocaine block of neonatal $\mathrm{Na}_{\mathrm{v}} 1.3$ is differentially modulated by co-expression of betal and beta3 subunits. Eur. J. Pharmacol. 467, 23-30 (2003).

52. Zhang, M. M. et al. Co-expression of $\mathrm{Na}_{\mathrm{v}} \beta$ subunits alters the kinetics of inhibition of voltage-gated sodium channels by pore-blocking mu-conotoxins. Br. J. Pharmacol. 168, 1597-1610 (2013).

53. Wilson, M. J. et al. $\mathrm{Na}_{\mathrm{v}} \beta$ subunits modulate the inhibition of Nav1.8 by the analgesic gating modifier muO-conotoxin MrVIB. J. Pharmacol. Exp. Ther. 338, 687-693 (2011).

54. Isom, L. L. Sodium channel beta subunits: anything but auxiliary. Neuroscientist 7, 42-54 (2001).

55. Isom, L. L. \& Catterall, W. A. $\mathrm{Na}^{+}$channel subunits and Ig domains. Nature 383, 307-308 (1996).

56. Isom, L. L. The role of sodium channels in cell adhesion. Front. Biosci. 7, 12-23 (2002).

57. Hernandez-Plata, E. et al. Overexpression of $\mathrm{Na}_{\mathrm{v}} 1.6$ channels is associated with the invasion capacity of human cervical cancer. Int. J. Cancer. 130, 2013-2023 (2012).

58. Jezequel, P. et al. bc-GenExMiner: an easy-to-use online platform for gene prognostic analyses in breast cancer. Breast Cancer Res. Treat. 131, 765-775 (2012).

59. Gore, J., Besson, P., Hoinard, C. \& Bougnoux, P. Na( $\left.{ }^{+}\right)-\mathrm{H}^{+}$antiporter activity in relation to membrane fatty acid composition and cell proliferation. Am. J. Physiol. 266, C110-C120 (1994).

60. Soderberg, O. et al. Direct observation of individual endogenous protein complexes in situ by proximity ligation. Nat. Methods 3, 995-1000 (2006).

61. Westerfield, M. The Zebrafish Book: A Guide for the Laboratory Use of Zebrafish (Danio rerio) 5th edn (Univ. Oregon Press, 2007)..

\section{Acknowledgements}

This work was supported by the 'Ministère de la Recherche et des Technologies', the Inserm, the 'Ligue Nationale Contre le Cancer-Interrégion Grand-Ouest', the Région 
Centre (grant ' $\mathrm{Na}_{\mathrm{V}}$ Metarget', project 'ARD2020 Biomédicaments') and the 'Association CANCEN'. J.L.G.-P. was supported by 'Le Studium'. We thank Mrs Catherine Le Roy for secretary and administrative assistance, and Dr Armelle Vinceneux for her help with IHC staining of $\beta 4$ in human breast normal tissues. We thank Prof. Stephan J. Reshkin (University of Bari, Italy), Dr Lin-Hua Jiang (University of Leeds, UK) and Dr Philippe Chavrier (Institut Curie, France) for their critical reading of the manuscript.

\section{Author contributions}

All authors contributed extensively to the work presented in this study. E.B. performed and analysed immunofluorescence imaging, time-lapse microscopy experiments, assessed cell adhesion and transendothelial migration. E.B., V.D. and F.G. performed cell culture, molecular and cellular biology experiments, assessed cell viability, migration and invasion. E.B., V.D., M.A. and M.-L.C. performed zebrafish experiments. I.D. participated to cell culture. C.M.-C. and P.P. performed and analysed immunohistochemical experiments on tissue microarrays, and R.G. and G.F. on mice tissues. S.M.-L. and T.O. performed mice experiments, E.B., S.R., S.C. and P.B. analysed in vivo data. E.B., V.D., E.P. and A.M. participated to lentiviral particles production and the generation of small hairpin RNA or overexpressing cancer cell lines. S.R performed electrophysiology experiments. E.B., F.G. and J.B.-G. performed scanning electron microscopy experiments. J.B.-G. and S.R. performed in silico expression analyses. P.G.F. contributed in discussion and correction of the manuscript. S.R., S.C. and P.B. obtained research grants, directed the research, designed the study, analysed the data and wrote the manuscript.

\section{Additional information}

Supplementary Information accompanies this paper at http://www.nature.com/ naturecommunications

Competing financial interests: The authors declare no competing financial interests.

Reprints and permission information is available online at http://npg.nature.com/ reprintsandpermissions/

How to cite this article: Bon, E. et al. SCN4B acts as a metastasis-suppressor gene preventing hyperactivation of cell migration in breast cancer. Nat. Commun. 7, 13648 doi: 10.1038/ncomms13648 (2016).

Publisher's note: Springer Nature remains neutral with regard to jurisdictional claims in published maps and institutional affiliations.

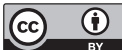

This work is licensed under a Creative Commons Attribution 4.0 International License. The images or other third party material in this article are included in the article's Creative Commons license, unless indicated otherwise in the credit line; if the material is not included under the Creative Commons license, users will need to obtain permission from the license holder to reproduce the material. To view a copy of this license, visit http://creativecommons.org/licenses/by/4.0/

(C) The Author(s) 2016 